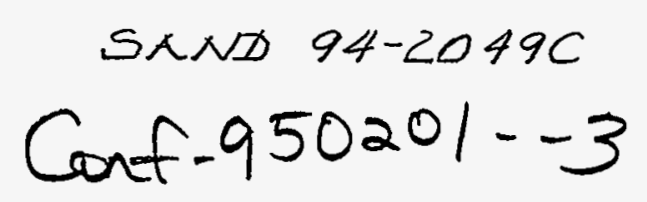

\title{
Cavity Formation and Impurity Gettering in He-Implanted Si
}

\author{
D. M. Follstaedt, S. M. Myers, G. A. Petersen and J. W. Medernach \\ Sandia National Laboratories \\ Albuquerque, New Mexico 87185-1056
}

\begin{abstract}
Cavity microstructures formed in Si after ion implantation of $\mathrm{He}$ and annealing at $700^{\circ} \mathrm{C}$ or above are examined with cross-section transmission electron microscopy. A threshold concentration of 1.6 at.\% $\mathrm{He}$ is identified to form cavities that survive such anneals. The cavities coarsen with a constant volume of $15 \mathrm{~nm}^{3} / \mathrm{nm}^{2}$ (per wafer surface area), corresponding to $\sim 0.75$ lattice sites per implanted He atom. The internal area of the cavities is 3-7 times that of the wafer surface area for fluences of $1 \times 10^{17} \mathrm{He} / \mathrm{cm}^{2}$. Transition metal atoms $(\mathrm{Cu}, \mathrm{Ni}, \mathrm{Co}, \mathrm{Fe}, \mathrm{Au})$ are shown to be strongly trapped (1.5 - 2.2 $\mathrm{eV}$ ) on the cavity walls by chemisorption. Whereas $\mathrm{Cu}, \mathrm{Au}$ and $\mathrm{Ni}$ are bound more strongly to the cavity sites than to their respective precipitated phases, $\mathrm{Co}$ and $\mathrm{Fe}$ are more strongly bound to their silicides; nonetheless, appreciable trapping of $\mathrm{Co}$ and $\mathrm{Fe}$ does occur in equilibrium with the silicides. Cavity trapping appears to be an effective gettering mechanism at low impurity levels, as needed to meet future microelectronics device requirements.
\end{abstract}

\section{Introduction}

Transition-metal impurities are known to cause detrimental effects in Si microelectronics, and gettering is used to reduce their concentrations in device regions [1, and a series of articles in 2]. Most methods presently in use are based on inducing precipitation of metal silicides [1], which can reduce an impurity concentration down to its solid solubility, $\mathrm{C}_{\mathrm{sp}}$. The solubilities of transition metals are found to be greater than $10^{12} / \mathrm{cm}^{3}$ at temperatures where measurable [3]. However, metallic impurity specifications are expected to be as low as $10^{9}$ atoms $/ \mathrm{cm}^{3}$ for future devices [4]. Thus more effective gettering methods will be needed. A recently identified method is to implant $\mathrm{C}$, which has been found to bind $\mathrm{Au}$ and $\mathrm{Cu}$ strongly [5]. These doped layers are currently being evaluated to quantify their gettering efficacy and to learn the detailed atomic mechanism involved.

Here we discuss our work investigating a new gettering mechanism, chemisorption on the walls of cavities formed by $\mathrm{He}$ implantation. Helium has a low solubility in $\mathrm{Si}$ and forms bubbles a few nanometers in diameter when implanted at room temperature [6,7]. Upon annealing at $700^{\circ} \mathrm{C}$ or higher, the He outgasses from the specimen, but the cavities formed persist and coarsen. Figure 1 shows two cross-section transmission electron microscopy (TEM) images of subsurface cavity layers formed by implanting $1 \times 10^{17} \mathrm{He} / \mathrm{cm}^{2}$ at $30 \mathrm{keV}$ and subsequently annealing. For $700^{\circ} \mathrm{C}$ anneals, well defined cavities with $8.5 \mathrm{~nm}$ average diameter are observed in a subsurface layer between depths of 0.15 and $0.35 \mu \mathrm{m}$; the overlayer appears almost cavity 


\section{DISCLAIMER}

Portions of this document may be illegible in electronic image products. Images are produced from the best available original document. 
free. After the $900^{\circ} \mathrm{C}$ anneal the cavities are much larger, $20 \mathrm{~nm}$ average diameter. Facets are observed in both instances, with $\{111\}$ planes being dominant. The dangling bonds of the $\mathrm{Si}$ atoms on cavity walls are expected to be highly reactive, and as shown below, metal impurity atoms bind strongly to them [8-12]. The cavities evolve with temperature, but persist even near $1200^{\circ} \mathrm{C}$ as might be needed for device processing. Thus the cavity surface sites are reversible traps for metal impurities in the Si lattice. As a gettering mechanism, this trapping offers a distinct thermodynamic advantage over conventional precipitation mechanisms: trapping will persist at arbitrarily low concentrations, and maintain a constant proportionality between the amount of impurity remaining in solution and the fractional occupation of the trapping sites. Moreover, He implantation and gettering on the front side of the wafer may be consistent with device production, which is important for future processing which requires lower temperatures and correspondingly reduced diffusion distances available for gettering.

We first discuss the threshold concentration for stable cavity formation and quantify the evolution of the cavity microstructure with annealing. Then experiments demonstrating that $\mathrm{Cu}$ is bound more strongly to cavity walls than to $\eta-\mathrm{Cu}_{3} \mathrm{Si}$ are summarized. Microstructural information is used with the amount of bound $\mathrm{Cu}$ to interpret the binding mechanism in this well studied example. The chemisorptions of $\mathrm{Au}$ and $\mathrm{Ni}$ to cavity walls are also stronger than the bindings to their precipitated phases. However, $\mathrm{Ni}$ exhibits a reduced level of trap saturation, which we interpret as due to an ordered Ni-Si surface structure on the cavity walls. Finally, cavity-wall trappings of $\mathrm{Co}$ and $\mathrm{Fe}$ are demonstrated, although at low coverages indicating that these metals are more strongly bound to their silicides than to cavities. While these elements provide a survey of trapping phenomena, they are also of direct interest to microelectronics technology. Commonly observed contaminants in devices include $\mathrm{Cu}, \mathrm{Ni}, \mathrm{Co}$ and $\mathrm{Fe}$. Copper is of special concern because it is highly mobile in $\mathrm{Si}$, and low concentrations of $\mathrm{Cu}$ can cause fatal defects in devices.

Much of our work used an implantation energy of $30 \mathrm{keV}$ to produce a peak He concentration well below the surface $\left(R_{p}=0.3 \mu \mathrm{m}\right)$ and a cavity layer width $(\sim 0.2 \mu \mathrm{m}$; see Fig. 1) suitable for profiling metallic elements within it by Rutherford backscattering spectroscopy (RBS) using 2.5 $\mathrm{MeV} \mathrm{He}$. The metallic impurities were introduced by ion implantation at $150 \mathrm{keV}$ into floatzone (FZ) Si. Since the amounts of trapped Fe and Co are too small to be detected with RBS, their profiles were obtained by secondary ion mass spectroscopy (SIMS) and sputter depth profiling. The SIMS concentrations were calibrated against standard samples prepared by ion implantation, and sputtered depths were calibrated against profilometry measurements of the depth. Cross-section TEM specimens were prepared by specialized metallographic polishing and ion milling [13]. The TEM images were obtained with $200 \mathrm{keV}$ or $300 \mathrm{keV}$ instruments capable of $0.27 \mathrm{~nm}$ or $0.23 \mathrm{~nm}$ resolution, respectively. To observe cavities with minimal contrast from the accompanying lattice damage, specimens were tilted from their [110] orientation by several degrees to reduce diffraction effects and imaged in an underfocussed condition to highlight the cavity edges with Fresnel contrast. 


\section{Cavity Formation and Evolution}

\section{Nucleation of Stable Cavities}

Lower He fluences than that of Fig. 1 were examined to identify conditions for stable cavity formation after annealing $1 / 2 \mathrm{hr}$. at $700^{\circ} \mathrm{C}$. Figure 2 shows lower-magnification cross-section TEM images with narrower cavity layers produced by implanting $1 \times 10^{16} \mathrm{He} / \mathrm{cm}^{2}$ and $2 \times 10^{16}$ $\mathrm{He} / \mathrm{cm}^{2}$. The lowest fluence formed an intermittent layer with clusters of cavities located at a depth of $0.3 \mu \mathrm{m}$, while the higher fluence produced a continuous layer of cavities with a width of $65 \mathrm{~nm}$. These two results indicate that a threshold has been crossed with this increase in fluence. We interpret this threshold and the reduced width for $2 \times 10^{16} \mathrm{He} / \mathrm{cm}^{2}$ as a concentration threshold for the formation of cavities that persist after the anneal. The threshold is between the peak concentrations of these two implantations; 0.9 at.\% and 1.8 at.\% He are predicted using the TRIM90 Monte Carlo simulation program [14]. The TRIM profile for $2 \times 10^{16} \mathrm{He} / \mathrm{cm}^{2}$ is shown in Fig. 3 after adjusting the TRIM depth scale and $R_{p}$ by $\sim 10 \%$ to fit the observed cavity depth. Fitting the width of the cavity layer to this calculated profile gives a threshold concentration of $\mathrm{C}_{t}$ $=1.6$ at. $\%$ as shown in Fig. 3 . Exceeding $C_{t}$ could also be the criterion for forming cavities after the implantation at room temperature; cavities 1-2 $\mathrm{nm}$ in diameter have been observed without annealing [15].

The threshold for stable cavity formation was also examined using $130 \mathrm{keV} \mathrm{He}$ implantation [16]. An incomplete cavity layer was also observed for a fluence of $1 \times 10^{16} \mathrm{He} / \mathrm{cm}^{2}$ after annealing at $700^{\circ} \mathrm{C}$, while a continuous cavity layer was again observed for $2 \times 10^{16} \mathrm{He} / \mathrm{cm}^{2}$. In addition, a fluence of $1 \times 10^{15} \mathrm{He} / \mathrm{cm}^{2}$ produced no evidence for cavity formation, and did not produce detectable dislocations in cross-section TEM examination.

Lattice damage is closely associated with the cavity structures that survive annealing. The residual diffraction contrast in Fig. 2a indicates the presence of extended defects at the cavity clusters for the $1 \times 10^{16} \mathrm{He} / \mathrm{cm}^{2}$ implantation. Diffraction contours encircle the clusters, indicating that there is significant strain around them. Imaging with strongly diffracting two-beam conditions for $\{111\}$ or $\{220\}$ (not shown) clearly demonstrate extended lattice defects (dislocations and/or planar faults) localized at each cluster. Such imaging with the $2 \times 10^{16}$ $\mathrm{He} / \mathrm{cm}^{2}$ specimen also shows damage continuously along the cavity layer, and extensive dislocation networks are seen among cavities in layers implanted with $1 \times 10^{17} \mathrm{He} / \mathrm{cm}^{2}$.

Defects are expected to play an important role in nucleating bubbles and forming stable cavities. The details of the process are not known, but certain features appear likely to influence the process and the nucleation threshold. Since the observed threshold is far above the solubility of $\mathrm{He}$ in $\mathrm{Si}$; bubble formation is thermodynamically allowed at much lower concentrations, but is apparently inhibited. A plausible scenario is that He atoms implanted to concentrations below $C_{t}$ are trapped in isolation from each other by lattice damage produced by the implantation, and are unable to accumulate into bubbles. As more He is implanted, these damage sites become saturated and additional He atoms accumulate at existing $\mathrm{He}$ sites; defects with open volume should be favored as trapping centers. For concentrations above $C_{t}$, these sites serve as 
nucleation centers for bubbles, which probably form at room temperature [13]. The remaining isolated $\mathrm{He}$ is known to become mobile on heating to $700^{\circ} \mathrm{C}[6,7]$, and can contribute to enlarging the bubbles, if it encounters them. If too few nucleation centers are present, as for the $1 \times 10^{16} \mathrm{He} / \mathrm{cm}^{2}$ fluence, much of the He will diffuse out of the specimen during the anneal without enlarging the bubbles.

The formation of bubbles requires removing atoms to make cavities in the Si. Two possible mechanisms for forming the open volume can be recognized: isolated vacancies could collect at bubbles to reduce the compressive strain in the lattice around them, or interstitial dislocation loops could be "punched" from the bubbles to relieve their high internal pressures [17]. Although a continuous cavity layer is not formed for the $1 \times 10^{16} \mathrm{He} / \mathrm{cm}^{2}$, the isolated cavities allow apparent nucleation sites to be observed with less interference from neighboring sites. The extended lattice damage (dislocations and planar defects) centered on each site may be evidence of loop punching. It is notable that some clusters have a larger central cavity surrounded by smaller ones, suggesting a cooperative nature to bubble nucleation.

\section{Cavity Evolution and Thermal Stability}

Using TEM to quantitatively evaluate the microstructure provides additional insight into cavity evolution. The number of cavities and their area and volume were obtained by counting and sizing them in cross-section images; these quantities were normalized to the front wafer area by measuring specimen thickness using diffraction thickness fringes [13] or convergent-beam diffraction methods [18]. A size distribution with $2 \mathrm{~nm}$ increments was made using each cavity's largest observed diameter, since it is readily identified for all cavities. The distribution for an anneal of 10 hours at $800^{\circ} \mathrm{C}$ is shown in Fig. 4. Volume and area were then computed from such distributions by ignoring any assymmetries and treating all the cavities as spheres. Table I summarizes this information for two fluences and several anneal temperatures. The cavity volume (per wafer front-surface area) for our highest fluence, $1 \times 10^{17} \mathrm{He} / \mathrm{cm}^{2}$, is essentially constant (within experimental uncertainty of about $15 \%$ ) at temperatures $\geq 700^{\circ} \mathrm{C}$ where the $\mathrm{He}$ has been released; we take $15 \mathrm{~nm}^{3} / \mathrm{nm}^{2}$, obtained at $900^{\circ} \mathrm{C}$ where the cavities are largest and errors are less likely. Using the density of $\mathrm{Si}\left(5.0 \times 10^{22} \mathrm{Si} / \mathrm{cm}^{3}\right)$ with this volume gives $0.75 \times 10^{17}$ lattice sites $/ \mathrm{cm}^{2}$, or 0.75 sites per implanted He atom. This value indicates that the He density in cavities approaches that of solid Si. Another relevant comparison comes from the Van der Waals volume for He gas atoms [19]: 0.0237 liters $/ \mathrm{mole}$, which gives a density of $2.5 \times 10^{22} \mathrm{He} / \mathrm{cm}^{3}$ if the gas were compressed to this "hard sphere" volume. An estimate of the He density in the cavities is obtained by dividing the fluence by the cavity volume, which gives $6.7 \times 10^{22} \mathrm{He} / \mathrm{cm}^{3}$. This value exceeds the density obtained from the Van der Waals gas parameter, which suggests that high pressures occurred during bubble formation, and cavity volume could have been produced by punching interstitial loops [17].

Coarsening of the cavities with increasing temperature is apparent in Fig. 1, and for constant volume the surface area decreases as seen in Table I. The cavity distribution in Fig. 4 peaks at small sizes $(12 \mathrm{~nm})$ and slowly decreases to zero at about $40 \mathrm{~nm}$. Such a distribution is skewed in the opposite direction for conventional second-phase ripening; in that case, smaller 
precipitates dissolve and their solute diffuses to larger ones, while the distribution becomes skewed toward larger sizes [20]. The distribution in Fig. 4 thus argues against growth of cavities by preferential dissolution of vacancies (which would be the "solute" here) from small cavities and ripening of larger ones. Instead, cavities enlarge by migrating into one another and coalescing, as observed directly by in situ heating of He-implanted Si by Griffioen et al. [6]. In some of our images elongated cavities are be seen (see Fig. 1b) and may have resulted from a recent coalescence. Such migration occurs by internal surface diffusion of atoms between the walls of the cavities.

More can be learned about the critical He concentration by considering the cavity volume for the $2 \times 10^{16} \mathrm{He} / \mathrm{cm}^{2}$ fluence. Using all the implanted $\mathrm{He}$, this volume corresponds to 0.56 sites per implanted $\mathrm{He}$ atom, close to that for $1 \times 10^{17} \mathrm{He} / \mathrm{cm}^{2}$. However, $80 \%$ of the He distribution is outside the depth interval where cavities are found to remain after annealing; see Figs $2 b$ and 3 . If only the He within this interval were used, the volume per atom would be far greater than for $1 \times 10^{17} \mathrm{He} / \mathrm{cm}^{2}$ ( 2.8 vs. 0.75 ). This implies that when He located at depths with concentrations below $\mathrm{C}_{\mathrm{t}}=1.7$ at.\% becomes mobile as the temperature rises, it also collects into bubbles and increases their volume. All the He returns to solution and diffuses out of the specimen when temperatures of $700^{\circ} \mathrm{C}$ or higher are reached.

Two observations indicate the thermal stability of the cavities. First, the cavity volume is constant for anneals up to $900^{\circ} \mathrm{C}$. This indicates that Si interstitials, which must be present after cavity formation, are not refilling the cavities; since the average cavity diameter is larger at $1000^{\circ} \mathrm{C}$, refilling apparently does not occur below this temperature. Second, Fig. 5 shows a cross-section TEM image for $2 \times 10^{16} \mathrm{He} / \mathrm{cm}^{2}$ implanted at $130 \mathrm{keV}$ and subsequently annealed $1 / 2 \mathrm{hr}$. at $700^{\circ} \mathrm{C}$ in dry $\mathrm{O}_{2}$. Cavities from this treatment are formed in a continuous layer at 0.7 $\mu \mathrm{m}$ depth, as expected for the He projected range. This specimen was subsequently baked in $\mathrm{H}_{2}$ gas for 5 minutes at $1180^{\circ} \mathrm{C}$ to remove surface oxide and then a $1.5 \mu \mathrm{m}$ overlayer of epitaxial $\mathrm{Si}$ was grown by chemical vapor deposition at $1120^{\circ} \mathrm{C}$. Cavities and their associated dislocations are still seen at their original implanted position, now $2.2 \mu \mathrm{m}$ below the surface. The cavity volume was not quantitatively analyzed, but it is clear that the cavities survived this treatment, one of the highest-temperature processes for Si devices. A more complete microstructural investigation of $\mathrm{He}$ implantation and cavities relating to device processing will be given elsewhere [16]. 


\section{Monolayer Binding on Cavity Walls: $\mathrm{Cu}$ and $\mathrm{Au}$}

The quantitative evaluation of solute transport in $\mathrm{Si}$ requires mathematical modeling of several thermodynamic reactions and the kinetic processes controlling them. Diffusion must be treated both in pure $\mathrm{Si}$ and in the presence of the trapping sites. We have developed such a model which includes source terms in the diffusion equation to account for exchange of solute atoms between trapping sites and mobile solution sites [21]. The trapping sites are given a depth dependence which accounts for the He projected range and the cavity distribution width seen in Fig. 1, and can handle transport from silicide to cavities on the opposite side of the wafer. The solute transport is then obtained through numerical solution using finite depth increments and sufficiently small time increments to obtain convergence. At the precipitates, a condition of "near equilibrium" is maintained locally between the precipitated phase and the solid solution; a similar equilibration occurs around the cavities between the solid solution and the trapped solute. The two equations governing these equilibria are:

$$
\mathrm{C}_{\mathrm{sp}}=\mathrm{C}_{\mathrm{o}} \exp \left(-\mathrm{Q}_{\mathrm{p}} / \mathrm{kT}\right)
$$

for solid solution and precipitates, where $\mathrm{C}_{\mathrm{s}}$ is the solution concentration expressed as an atomic fraction, $\mathrm{C}_{\mathrm{o}}$ is a temperature-independent factor, and $\mathrm{Q}_{\mathrm{p}}$ is the binding energy relative to solution, and

$$
\mathrm{C}_{\mathrm{st}}=\{\theta /[1-\theta]\} \exp \left(-\mathrm{Q}_{\mathrm{t}} / \mathrm{kT}\right)
$$

for solution and traps, where $\theta$ is the average fractional occupancy of the traps. In implementing (2), it is assumed that cavity surface binding sites are not influenced by the occupation of neighboring sites. The physical picture is one of independent, single-atom trapping sites. Note that $\mathrm{C}_{\mathrm{sp}}$ is the solid solubility of the silicide phase and is independent of the number of precipitated atoms, while $\mathrm{C}_{\mathrm{st}} \propto \theta$ for $\theta<<1$, demonstrating that the solution concentration can be reduced below the solid solubility, provided $Q_{t}$ is greater than $k T$ and the trap sites are not saturated. With this modeling, solute transport can be checked against known solubilities and diffusivities, and bonding strength evaluated relative to solution.

\section{Chemisorption of $\mathrm{Cu}$ on Cavity Walls}

Copper was chosen to be studied first because it has the highest diffusivity of the transition elements [3] and moves readily through wafers at temperatures as low as $600^{\circ} \mathrm{C}$. The strong binding of $\mathrm{Cu}$ to cavity surface sites is clearly demonstrated with the following experiment. First, cavities were formed by implanting $1 \times 10^{17} \mathrm{He} / \mathrm{cm}^{2}$ at $30 \mathrm{keV}$ into one side of the wafer and annealing at $1 / 2 \mathrm{hr}$. at $700^{\circ} \mathrm{C}$. Next, silicide is formed on the other side of the $250 \mu \mathrm{m}$-thick wafer by implanting $1 \times 10^{17} \mathrm{Cu} / \mathrm{cm}^{2}$ at $150 \mathrm{keV}$ and annealing at $600^{\circ} \mathrm{C}$. This produces a peak $\mathrm{Cu}$ concentration of 10 at.\% at a depth of $62 \mathrm{~nm}$. Electron diffraction from the near-surface layer of a plan-view specimen annealed for 6 hours at $600^{\circ} \mathrm{C}$ gives the ring pattern shown in Fig. 6 [9]. The brightest rings are due to $\mathrm{Si}$ and are indicated with arrows. The remaining rings are listed in columns 1 and 2 of Table II and match those calculated for $\mathrm{Cu}_{3} \mathrm{Si}$ (column 3) using the basic hexagonal unit cell $(\mathrm{a}=4.04 \AA, \mathrm{c}=2.44 \AA)$ of Weber et al [22] to describe the $\eta$ phase. Additional lattice spacings in Fig. 6 and seen by others [23] (see column 4 of Table II) are apparently due to the ordering reactions that occur $\left(\eta \rightarrow \eta^{\prime} \rightarrow \eta^{\prime \prime}\right)$ when the silicide is cooled to 
room temperature. The polycrystals of $\mathrm{Si}$ and $\eta-\mathrm{Cu}_{3} \mathrm{Si}$ in the implanted layer are misoriented with respect to the single-crystal substrate, and are formed by amorphization of the $\mathrm{Si}$ by the $\mathrm{Cu}$ implant and the crystallization of the layer during the anneal. The crystals of $\mathrm{Cu}_{3} \mathrm{Si}$ in the surface layer were also identified in a cross-section specimen using diffraction and dark-field imaging [9].

The buildup of $\mathrm{Cu}$ at the cavities on the opposite side of the wafer was monitored during annealing at $600^{\circ} \mathrm{C}$ with RBS, and the depth-integrated amount is plotted versus time in Fig. 7. The amount first increases linearly and then saturates at $4.8 \times 10^{15} \mathrm{Cu} / \mathrm{cm}^{2}$. The initial linear increase can be checked with expected solute transport from the silicide layer across the $250 \mu \mathrm{m}$ thick wafer to the cavities. The solid line in Fig. 7 was fitted to the data by adjusting the diffusivity and solubility of $\mathrm{Cu}$ in $\mathrm{Si}$. The values obtained are in good agreement with published values for these parameters at $600^{\circ} \mathrm{C}[11]$, including the heat of solution, $Q_{s}=1.7 \mathrm{eV}$, relative to $\mathrm{Cu}_{3} \mathrm{Si}$. The saturation level in Fig. 7 is compared in Table I with the expected number of bonding sites available, as obtained by using the TEM-measured cavity surface area and assuming $7 \mathrm{Si}$ bonds $/ \mathrm{nm}^{2}$ as available on $\{111\}$ or $1 \times 2$ reconstructed $\{100\}$ Si surfaces. The rather exact agreement with prediction is fortuitous given the $15 \%$ uncertainty in the TEM measurement, but is strong support for chemisorption bonding of $\mathrm{Cu}$ on the cavity walls, as assumed in the Introduction.

To confirm this trapping mechanism and demonstrate the $\sim 1$ monolayer (ML) coverage, the experiment was repeated using the same implantations but annealing the cavities $1 \mathrm{hr}$. at $900^{\circ} \mathrm{C}$ to enlarge them. After a $26 \mathrm{hr}$. anneal at $600^{\circ} \mathrm{C}$ to saturate the cavities with $\mathrm{Cu}$, the amount of trapped $\mathrm{Cu}$ was again found to agree with the number of sites predicted using the area measured with TEM, as seen in Table I. A cross-section TEM specimen was prepared to examine the cavities saturated with $\mathrm{Cu}$. Second phases were searched for using diffraction and its contrast in bright-field images, but were not detected. In another approach, we used lattice imaging through cavities to look for new lattice spacings; as seen in Fig. 8, the image shows only the lattice periodicity of $\mathrm{Si}$, with an abrupt change in contrast at the cavity wall. In some cases, one atomic layer with darker contrast was observed on $\{111\}$ facet planes, which could be due to trapped $\mathrm{Cu}$ or perhaps a reconstruction of the surface. The $\{110\}$ planes were also prominent as facets in the images; detailed examination and comparison with faceting of empty cavities [24] suggests that when saturated with $\mathrm{Cu}$, these planes may be slightly lower in relative free energy (w.r.t. $\{111\}$ ) than they were in empty cavities. The two $\{100\}$ planes are seen on the cavity surface but exhibit rounding toward the $\{111\}$ planes, just as for empty cavities; in some cases, $\{311\}$ planes could be resolved between these two types of facets. Altogether, the faceting indicates that $\mathrm{Cu}$ is binding to $\{111\},\{110\}$ and $\{100\}$ planes on the cavity walls.

The role of cavities in trapping $\mathrm{Cu}$ is also indicated by considering the trapped amount as a function of the He fluence. Shown in Fig. 9 are $\mathrm{Cu}$ depth profiles within the cavity layer for three fluences implanted at $30 \mathrm{keV}$. For $1 \times 10^{17} \mathrm{He} / \mathrm{cm}^{2}$, the Cu profile has a peak at the depth of the cavities $(0.3 \mu \mathrm{m})$, and its width and shape (skewed toward greater depths) are as observed with TEM and predicted by TRIM. For $2 \times 10^{16} \mathrm{He} / \mathrm{cm}^{2}$, the amount of $\mathrm{Cu}$ is reduced to $8 \times 10^{14}$ $\mathrm{Cu} / \mathrm{cm}^{2}$, consistent with that predicted from the cavity area (Table I). Note that the $\mathrm{Cu}$ 
distribution is also narrower, in agreement with Fig. $2 \mathrm{~b}$. We attempted to fit this profile to a central portion of the TRIM profile obtained by assuming a threshold concentration as before. However, when the amount of trapped $\mathrm{Cu}$ is compared to the amount of $\mathrm{He}$ in this interval, too high a ratio results $(0.35 \mathrm{Cu} / \mathrm{He})$. When all the $\mathrm{He}\left(2 \times 10^{16} \mathrm{He} / \mathrm{cm}^{2}\right)$ is included, a ratio of 0.04 $\mathrm{Cu} / \mathrm{He}$ is obtained, in reasonable agreement with that for $1 \times 10^{17} \mathrm{He} / \mathrm{cm}^{2}, 0.05 \mathrm{Cu} / \mathrm{He}$. Such a comparison of $\mathrm{Cu}$ to $\mathrm{He}$ is valid since the cavity diameters (Table I) and thus the surface area/He atom are comparable for the two fluences. To fit the profiles, a threshold concentration was assumed; the best fit was obtained with a concentration of 1.25 at.\% He, somewhat lower than found from TEM images of the cavity layer width. The resolution of RBS in measuring $\mathrm{Cu}$, $\sim 10 \mathrm{~nm}$, may result in a lower value being identified. Finally, $\mathrm{Cu}$ trapping was attempted with $1 \times 10^{16} \mathrm{He} / \mathrm{cm}^{2}$ but none was detected, in agreement with the very few cavities seen in Fig. $2 \mathrm{a}$. This result indicates that at least $\sim 2 \times 10^{16} \mathrm{He} / \mathrm{cm}^{2}$ is needed to getter $\mathrm{Cu}$ effectively.

The buildup of $\mathrm{Cu}$ to the saturation level in Fig. 7 can be evaluated to obtain a lower limit on the binding energy, $Q_{t} \geq 1.3 \mathrm{eV}$. Only a lower limit is obtained because near saturation $\theta \rightarrow 1$, and the divergence in Eq. (2) causes $Q_{t}$ to be very sensitive to small uncertainties in $\theta$. We use a conservative estimate, $\theta \geq 0.5$, and then equate $C_{s p}$ and $C_{s t}$ in Eqs. (1) and (2), since silicides, solid solution, and trapped solute are all in equilibrium when saturation is achieved. This approach produces the lower bound on $Q_{t}$. In another type of experiment $[10,25]$ one cavity layer was saturated with $\mathrm{Cu}$, and then a second layer introduced. We examined the temperature at which redistribution occurred and $Q_{t}$ is less sensitive to $\theta$ to obtain $Q_{t}=2.2 \pm 0.2 \mathrm{eV}$ for the binding of isolated $\mathrm{Cu}$ atoms on the $\mathrm{Si}$ cavity surfaces. This rather large value indicates the efficacy of cavities as traps for $\mathrm{Cu}$; moreover, the increased binding over that of the silicide is indicated by comparing to the heat of solution, $1.7 \mathrm{eV}$.

\section{Chemisorption of Au to Cavity Surfaces}

To study the binding of $\mathrm{Au}, 1.6 \times 10^{16} \mathrm{Au} / \mathrm{cm}^{2}$ were first implanted into (001) Si at $300 \mathrm{keV}$ $\left(R_{p}=100 \mathrm{~nm}\right)$ and annealed $1 \mathrm{hr}$. at $850^{\circ} \mathrm{C}$. The $\mathrm{Au}$ reacts with the $\mathrm{Si}$ to form molten liquid at temperatures above the eutectic point $\left(363^{\circ} \mathrm{C}\right)$, according to their phase diagram [26]; solidification to $\mathrm{Si}$ and fcc $\mathrm{Au}$ is expected upon cooling to room temperature. Then, $1 \times 10^{17}$ $\mathrm{He} / \mathrm{cm}^{2}$ was implanted at $150 \mathrm{keV}\left(\mathrm{R}_{\mathrm{p}}=800 \mathrm{~nm}\right)$, and annealing at $850^{\circ} \mathrm{C}$ was continued to allow $\mathrm{Au}$ to diffuse from the implanted layer to the cavity layer $\approx 700 \mathrm{~nm}$ deeper. The $\mathrm{Au}$ accumulated to the $\mathrm{He}$ layer in a depth profile that scales with that of the $\mathrm{He}$, and saturated at $3.2 \times 10^{15} \mathrm{Au} / \mathrm{cm}^{2}$ after annealing 3 or more hours as seen in Fig. 10. The second set of data was obtained in a similar experiment but with annealing at $800^{\circ} \mathrm{C}$. To fit the linear buildup of trapped $\mathrm{Au}$ at the cavities, we adjusted the diffusivity and solubility to obtain the solid line in Fig. 10. The two values fall between two reported values for the diffusivity/solubility product [4, 27]. As shown in Table I, the saturated level is consistent with the surface areas found for similar anneals in this temperature regime, assuming $\sim 1 \mathrm{Au} / \mathrm{Si}$ atomic binding. While we have not examined detrapping of $\mathrm{Au}$ from cavities to quantify the binding energy precisely, a lower limit can again be obtained: $Q_{t} \geq 2.0 \mathrm{eV}$. 
These results indicate that the binding energy of $\mathrm{Au}$ is comparable to $\mathrm{Cu}$, and that $\mathrm{Au}$ trapping also saturates at $\sim 1 \mathrm{ML}$ cavity wall coverage. In work done by Wong-Leung et al. [28], the interaction of $\mathrm{Au}$ with cavities formed by implanting $\mathrm{H}$ has been studied in detail. In their experimental configuration, the Au migrates to the cavities and precipitates there, presumably via the eutectic reaction. We believe this observation does not contradict ours, but rather that the two results reflect the differing experimental configurations. In the work by Wong-Leung et al, the cavities are present before the Au becomes mobile and reacts with Si. Upon annealing the amorphous Au-implanted $\mathrm{Si}$, crystallization occurs and is expected to produce a metastable supersaturated solution. The cavities are then an ideal nearby site to precipitate the $\mathrm{Au}$, although some precipitation also occurs near the wafer surface. (Similarly, $\mathrm{Cu}_{3} \mathrm{Si}$ was observed for $\mathrm{Cu}$ when implanted near a pre-existing cavity layer [29].) In our case, the Au was deliberately "prereacted" to eliminate the metastable solution and the cavities subsequently introduced at a wellseparated position; the Au then diffuses in solid solution to them at a concentration governed by Eq. (1), followed by chemisorption trapping on the cavity walls. Precipitation at the cavities does not occur with our approach because the thermodynamic driving force to do so has been removed by reacting the $\mathrm{Au}$ and $\mathrm{Si}$. 


\section{Trap Saturation at Lower Coverage: Ni}

For $\mathrm{Cu}$ and $\mathrm{Au}$ binding at cavities, $\sim 1 \mathrm{ML}$ of solute can be bound to the cavity surfaces. as discussed above. Similar experiments were done with $\mathrm{Ni}$, and the amount trapped at the cavities saturated at $\sim 1 / 20$-th the amount for $\mathrm{Cu}$, or $1.5 \times 10^{14} \mathrm{Ni} / \mathrm{cm}^{2}$ in work at $700^{\circ} \mathrm{C}$. Because silicide nucleation can be sluggish, TEM was used to verify that $\mathrm{NiSi}_{2}$ [26], had formed as required for thermodynamic equilibrium. In (001) Si implanted with $1 \times 10^{17} \mathrm{Ni} / \mathrm{cm}^{2}$ at $150 \mathrm{keV}$ and annealed 64 hours at $700^{\circ} \mathrm{C}$, large particles of $\mathrm{NiSi}_{2}$ formed in the implanted surface layer, as seen in Fig. 11. The microdiffraction patterns in Fig. 11 were obtained by tilting the particle to known zones for this fcc phase; the identification was confirmed by using energy-dispersive $\mathrm{x}$-ray analysis to demonstrate the expected $\mathrm{Ni}$ content and to distinguish the particles from fcc (diamond) $\mathrm{Si}$.

This reduced amount of bound Ni can be understood in terms of findings with external Si surfaces. For $\mathrm{Ni}$ on $\{111\} \mathrm{Si}$, a $\sqrt{ } 19$ ordered structure with $1 \mathrm{Ni}$ atom per unit cell was identified at high coverages $[30,31]$. Since $\{111\}$ planes are prominent cavity facets, we suggest that this structure formed on them; the lower saturated coverage is explained since the unit cell has 19 times the area of unreconstructed Si. Such ordered surface phases are found for many metals on $\mathrm{Si}$, including Co on $\{111\}$, where a $\sqrt{7}$ phase with one solute atom per cell has been identified $[32,33]$. We can expect that at the high surface coverages in our experiments when the amount of trapped metal saturates, such surface phases will form. However, for gettering in wafers, we are interested in cavity surfaces with low coverages of isolated solutes, where the thermodynamics of trapping (Eq. (2)) apply to reduce the concentration remaining in solid solution, i.e., the "lattice gas" of isolated impurities found at low coverages. This is the state that initially traps solutes from solid solution, as in the linear buildup seen for small amounts of trapped solute, e.g., in Figs. 7 and 10. Such a state is expected to form for low concentrations of any solute on a surface before an ordered structure, in thermodynamic analogy with having impurities in solid solution up to a solubility limit, above which a second phase forms. This behavior is seen with external surfaces; for instance, at low coverages of $\mathrm{Co}$, a cluster of $\mathrm{Si}$ atoms surrounds each Co atom. As the amount of Co is increased, these isolated structures eventually nucleate islands of the $\sqrt{ } 7$ phase with similar clusters in their unit cell. Similarly, both the lowcoverage, non-interacting solute state and the high-coverage, ordered state have been observed for $\mathrm{Ni}$ [29]. and $\mathrm{Fe}$ [34]. The density of solute in these ordered states is a measure of the distance that non-interacting solute atoms can approach each other and still bind independently to the Si surfaces; we use it to estimate $\theta$ in Eq. (2). When $\theta$ is evaluated for $\mathrm{Ni}$ using a saturated coverage reduced by a factor of $1 / 19$, a lower limit of $\mathrm{Q}_{\mathrm{t}} \geq 1.5 \mathrm{eV}$ can be obtained for its chemisorption energy.

Our discussions of $\mathrm{Cu}$ and $\mathrm{Au}$ above assumed that they bound in a 1:1 ratio with surface $\mathrm{Si}$ atoms, and the data in Table I indicate that this is essentially correct. However, for $\mathrm{Cu}$ on $\{111\}$ $\mathrm{Si}$, an ordered structure with an incommensurate periodicity of 5.55 unit cells has been identified with an $\sim 1 \mathrm{ML}$ saturated coverage [35,36]. More than one ordered structure have been seen for $\mathrm{Au}$ on $\{111\} \mathrm{Si}$ [37], but the Au coverages are also expected to saturate $\sim 1 \mathrm{ML}$. Thus our observed saturation levels for these two impurities are consistent with their known ordered phases, if these phases formed on our cavity walls. 


\section{Strong Silicide Binding: $\mathrm{Co}$ and Fe}

To investigate the trapping of $\mathrm{Co}$ and $\mathrm{Fe}$, we followed implantation and annealing schedules known from published findings to form silicides [38, 39]. Iron was implanted at room temperature to a fluence of $5 \times 10^{16} \mathrm{Fe} / \mathrm{cm}^{2}$ at $100 \mathrm{keV}$, followed by annealing $1 \mathrm{hr}$. at $520^{\circ} \mathrm{C}$ and then $2 \mathrm{hr}$. at $1000^{\circ} \mathrm{C}$. Helium was then implanted into the opposite side of the wafer to $1 \times 10^{17}$ $\mathrm{He} / \mathrm{cm}^{2}$ at $150 \mathrm{keV}$, and the specimen annealed for $2 \mathrm{hr}$. at $1000^{\circ} \mathrm{C}(1273 \mathrm{~K})$ to transport $\mathrm{Fe}$ to the cavities and equilibrate with them. The Fe profile is shown in Fig. 12 , along with the $\mathrm{He}$ profile calculated using TRIM after scaling slightly to reduce the He range, as discussed above. The Fe peaks at the appropriate depth and has a shape conforming to the cavity distribution predicted by TRIM90, but the integrated amount is only $1.2 \times 10^{13} \mathrm{Fe} / \mathrm{cm}^{2}$, much less than found for $\mathrm{Cu}, \mathrm{Au}$ or even $\mathrm{Ni}$ as discussed above.

Cobalt was implanted to $5 \times 10^{16} \mathrm{Co} / \mathrm{cm}^{2}$ at $100 \mathrm{keV}$ and $350^{\circ} \mathrm{C}$; the specimen was then annealed $1 \mathrm{hr}$. at $600^{\circ} \mathrm{C}$, followed by $2 \mathrm{hr}$. at $900^{\circ} \mathrm{C}$. Then $1 \times 10^{17} \mathrm{He} / \mathrm{cm}^{2}$ was implanted at 150 $\mathrm{keV}$ into the opposite side of the wafer and the specimen annealed $2 \mathrm{hr}$. at $900^{\circ} \mathrm{C}(1173 \mathrm{~K})$ to equilibrate with the cavities. The depth profile obtained by SIMS is again seen in Fig. 12 to conform to the expected He distribution, but the total amount is quite small, $6.6 \times 10^{12} \mathrm{Co} / \mathrm{cm}^{2}$.

In both cases, the amount of trapped solute is far less than a monolayer: $0.0062 \mathrm{ML} \mathrm{Fe}$ and $0.0026 \mathrm{ML}$ Co. Nonetheless, the cavities have been equilibrated with the silicides; i.e., there has been sufficient diffusion to transport much more solute to the cavities than has accumulated. The small amount of trapped solute reflects a weaker binding to the traps than to the silicides. These metals have a large value for $Q_{p}$ in Eq. (1), which reduces $C_{s p}$, and for a given value of $Q_{t}$ in Eq. (2), results in a small fraction $(\theta)$ of traps being occupied. We equate $C_{s p}$ and $C_{s t}$ in Eqs. (1) and (2) to evaluate the equilibrium between silicide, solid solution and traps; as a first approximation to evaluating $\theta$, the number of trapping sites calculated from the TEM cavity surface area (Table I) was reduced by a factor of $1 / 7$ for Co to account for the expected $\sqrt{7}$ ordered structure on $\{111\}$ facets $[32,33]$ and by $1 / 2$ for $\mathrm{Fe}$ [34]. We then obtained $\mathrm{Q}_{t} \sim 1.6 \mathrm{eV}$ and $\sim 1.7 \mathrm{eV}$, respectively. Because the traps were only partially occupied, $Q_{t}$ is less sensitive to $\theta$; nonetheless, since the saturated coverage is not certain, these values are not as accurately known as that for $\mathrm{Cu}$. 


\section{Discussion}

We have shown that chemisorption on cavity walls binds $\mathrm{Cu}$ quite strongly relative to solid solution. We have used the measured binding energy to calculate the effects of cavity trapping on $\mathrm{Cu}$ impurities in $\mathrm{Si}$, and find that the residual solute concentration is expected to be reduced by orders of magnitude after gettering. Cavity trapping is modeled in Fig. 13 using the $2.2 \mathrm{eV}$ binding energy relative to solution, $5 \times 10^{15}$ traps $/ \mathrm{cm}^{2}$ achieved with a fluence of $1 \times 10^{17} \mathrm{He} / \mathrm{cm}^{2}$ and an anneal at $700^{\circ} \mathrm{C}$, a $1 \mathrm{~mm}$-thick wafer, and an anneal at $600^{\circ} \mathrm{C}$ to getter impurities. The solute concentration remaining after gettering is then $\sim 10^{-7}$ times the initial value. Such a reduction is expected even for low initial concentrations. The solid solubility limit [40], which achievable by gettering methods relying on silicide precipitation, is also indicated and is seen to be much higher. If the initial $\mathrm{Cu}$ concentration is as high as $\sim 10^{14} / \mathrm{cm}^{3}$, cavity gettering is predicted to reduce the solution concentration to $\sim 10^{7} / \mathrm{cm}^{3}$, corresponding to an areal density of $\sim 10^{8} / \mathrm{cm}^{2}$ as required for future technologies [4]. To maintain effective gettering, the number of trapping sites must be large enough so that they do not become saturated. The TEM work with cavities indicates that concentrations $>1.6$ at.\% He are needed to nucleate a continuous layer of cavities, corresponding to fluences of $\sim 2 \times 10^{16} \mathrm{He} / \mathrm{cm}^{2}$ or more.

Table III summarizes our findings to date on solute trapping, and compares the chemisorption energy with the binding enthalpy in the precipitated phase [3]. The 3d transition elements form silicides, whereas $\mathrm{Au}$ undergoes a eutectic reaction with $\mathrm{Si}$ and forms a liquid alloy at the temperatures examined. The traps can be saturated with $\mathrm{Cu}, \mathrm{Ni}$ or $\mathrm{Au}$ when gettering from their precipitated phases, although Ni saturates at a lower level, probably due to formation of an ordered surface phase on $\{111\}$ facets. The heat of solution for silicides increases upon moving across the $3 \mathrm{~d}$ transition element row from $\mathrm{Cu}$ and $\mathrm{Ni}$ to $\mathrm{Co}$ and $\mathrm{Fe}$, and becomes larger than the trapping energy. Nonetheless, a substantial binding energy, $\sim 1.5 \mathrm{eV}$ relative to solution, was determined and can permit significant reductions in impurity solution concentrations.

Our work has concentrated on chemisorption binding because of its potential to reduce impurity concentrations in devices to very low levels. Other work has shown that cavities can act as precipitation sites for $\mathrm{Au}$ [28], and might be implemented using this mechanism. We infer that if cavities are introduced, they might be able to getter some species by chemisorption while reducing the levels of stronger silicide-formers like $\mathrm{Co}$ and $\mathrm{Fe}$ by providing improved precipitation sites for them.

Another study at our laboratory [16] has examined cavity structures after device processing steps. This study was done using Czolchralski (CZ) Si wafers as would be used for device fabrication. The cavities persist at processing temperatures up to $1180^{\circ} \mathrm{C}$, and $\mathrm{Si}$ can be grown epitaxially over them. For fluences $\geq 3 \times 10^{16} \mathrm{He} / \mathrm{cm}^{2}$ at $130 \mathrm{keV}$, dislocations resulting from the $\mathrm{He}$ implantation remain near the cavity layer. The higher $\mathrm{O}$ content of this material and the mobility of the $O$ interstitial must be considered for their effects on cavities at the high processing temperatures. To check the role of $\mathrm{O}$, SIMS profiling was done on cavities in the $\mathrm{CZ}$ $\mathrm{Si}$ after an anneal at $1050^{\circ} \mathrm{C}$ in dry $\mathrm{O}_{2}$. As seen in Fig. 14, $\mathrm{O}$ is also clearly gettered by the cavities; the double-peaked structure indicates that $O$ gettered from the overlayer and the 
substrate bind tightly to the first cavity surface they encounter. The $O$ reduces the number of available binding sites on cavity walls that can be used to trap metal impurities, but substantial sites remain $\left(\sim 4 \times 10^{14} / \mathrm{cm}^{2}\right)$ for a fluence of $5 \times 10^{16} \mathrm{He} / \mathrm{cm}^{2}$. The cavities also influence the electrical properties of the $\mathrm{Si}$ in their vicinity because the dangling bonds can charge either positively by trapping electrons or negatively with holes [41]. The electrical perturbation in the $\mathrm{Si}$ extends from the cavity layer outward over the Debye screening distance. This distance varies with doping of the semiconductor and its carrier density, and spreading resistance measurements show that its influence extends to $\sim 1 \mu \mathrm{m}$ for $\mathrm{n}$-type Si with a carrier density $\sim 10^{14} / \mathrm{cm}^{3}[16]$. Thus cavity layers need to be placed several microns away from active device regions. In other work [11] we have shown that introducing $\mathrm{H}$ into the cavity layer can displace trapped $\mathrm{Cu}$. Thus if cavities are to be used to reduce impurity levels in devices, the gettering step must not be followed by other processing steps that could introduce $\mathrm{H}$ to the traps. The investigations of dislocation behavior, electrical perturbation, and interaction with other solutes $(\mathrm{O}$ and $\mathrm{H})$ indicate that many factors must be considered in detail before cavity gettering can be applied to devices. To date, however, this application still appears viable. 


\section{Acknowledgments}

The authors thank M. P. Moran for capable assistance with TEM specimen preparation and characterization. Contributions by D. M. Bishop to the initial work with $\mathrm{Cu}$ are gratefully acknowledged. This work was supported by Division of Materials Sciences, Office of Basic Energy Sciences of the United States Department of Energy under Contract DE-AC0494AL85000.

\section{References}

1. W. Schröter, M. Seibt and D. Gilles, in Materials Science and Technology, vol. 4: Electronic Structure and Properties of Semiconductors, ed. W. Schröter (VCH Publishers, New York, 1991) pp. 539-589.

2. Semiconductor Silicon 1994, eds. H. R. Huff, W. Bergholz and K. Sumino, (Electrochemical Society Proceedings, Pennington, NJ, 1994) PV94-10, pp. 769-930.

3. E. R. Weber, in Properties of Silicon, EMIS Data Reviews, Series No. 4 (INSPEC, New York, 1988) pp. 409-452.

4. H. R. Huff, in Proceedings 4th International Symposium on ULSI, eds. G. Celler, E. Middlesworth and K. Hoh (Electrochemical Society Proceedings, Pennington, NJ, 1993) pp. 103-132.

5. H. Wong, N. W. Cheung and P. K. Chu, Appl. Phys. Lett. 52, 889 (1988).

6. C. C. Griffioen, J. H. Evans, P. C. de Jong and A. Van Veen, Nucl. Inst. Meth. B27, 417 (1987).

7. A. Van Veen, C. C. Griffioen and J. H. Evans, Mat. Res. Soc. Symp. Proc. 107, 449-454 (1988).

8. S. M. Myers, D. M. Follstaedt and D. M. Bishop, Mat. Res. Soc. Symp. Proc. 316, 33-38 (1994).

9. D. M. Follstaedt and S. M. Myers, Mat. Res. Soc. Symp. Proc. 316, 27-32 (1994).

10. S. M. Myers, D. M. Follstaedt and D. M. Bishop, Mater. Sci. Forum 143-147, 1635-40 (1994).

11. S. M. Myers, D. M. Follstaedt, D. M. Bishop and J. W. Medernach, in Semiconductor Silicon 1994, eds. H. R. Huff, W. Bergholz and K. Sumino (Electrochemical Society Proceedings, Pennington, NJ, 1994) PV94-10, pp. 808-819. 
12. S. M. Myers, D. M. Follstaedt, G. A. Peterson, C. H. Seager, H. J. Stein and W. R. Wampler, Proceedings of 9th International Conference on Ion Beam Modification of Materials 1995, Nuclear Instruments and Methods B, to be published.

13. D. M. Follstaedt, S. M. Myers, W. R. Wampler and H. J. Stein, Proceedings of the Electron Microscopy Society of America (San Francisco Press, 1992) Part I, 334-335.

14. J. F. Ziegler, J. P. Biersack and U. Littmark, The Stopping and Range of Ions in Solids (Pergamon Press, New York, 1985); J. F. Ziegler, private communication, 1990.

15. D. M. Follstaedt, S. M. Myers and H. J. Stein, Mat. Res. Soc. Symp. Proc. 279, 105-110 (1993).

16. J. W. Medernach, T. A. Hill, S. M. Myers and T. J. Headley, submitted to Journal of the Electrochemical Society.

17. G. W. Greenwood, A. J. E. Foreman and D. E. Rimmer, J. Nucl. Mater. 4, 305-324 (1959).

18. P. M. Kelly, A. Jostsons, R. G. Blake and J. G. Napier, Phys. Stat. Sol. (a) 31, 771-790 (1975).

19. P. W. Voorhees, J. Stat. Phys. 38, 231-252 (1985).

20. Handbook of Chemistry and Physics, 59th Edition, (CRC Press, West Palm Beach, FL, 1978) p. D-230.

21. S. M. Myers and D. M. Follstaedt, J. Appl. Phys. 65, 311 (1989).

22. G. Weber, B. Gillor and P. Barret, Phys. Stat. Sol. (a) 75, 567 (1983).

23. K. P. Mukherjee, J. Bandyopadhyaya and K. P. Gupta, Trans. Met. Soc. 245, 2335 (1993).

24. D. M. Follstaedt, Appl. Phys. Lett. 62, 1116 (1993).

25. S. M. Myers, D. M. Bishop, D. M. Follstaedt, H. J. Stein and W. R. Wampler, Mat. Res. Soc. Symp. Proc. 283, 549-555 (1993).

26. Binary Alloy Phase Diagrams, eds. T. B. Massalski, J. L Murray, L. H. Bennett and H. Baker, (American Society for Metals, Metals Park, Ohio, 1986); pp. 312, 313 (Au-Si), and pp. 1755,1756 (Ni-Si).

27. U. M. Gösele and T. Y. Tan, in Materials Science and Technology, Vol. 4, eds. R. W. Cahn, P. Haasen, E. J. Kramer and W. Schröter, (VCH Publishers, New York, 1991), pp. 197-248. 
28. J. Wong-Leung, C. Ascheron, M. Petravic, R. G. Elliman and J. S.Williams, Appl. Phys. Lett., in press.

29. C. E. Ascheron, J. Wong-Leung, M. Petravic, R. G. Elliman and J. S. Williams, Applied Physics Letters, in press.

30. A. E. Dolbak, B. Z. Olshanetsky, S. I. Stenin, S. A. Teys and T. A Gavrilova, Surf. Sci. 218, 37-54 (1989).

31. R. J. Wilson and S. Chiang, Phys. Rev. Lett. 58, 2575-2578 (1987).

32. P. A. Bennett, M. Copel, D. Cahill, J. Falta and R. M. Tromp, Phys. Rev. Lett. 69, 1224-1227 (1992).

33. M.-H. Tsai, J. D. Dow, P. A. Bennett and D. G. Cahill, Phys. Rev. B48, 2486-2492 (1993).

34. T. Urano, M. Kaburagi, S. Hongo and T. Kanaji, Appl. Surf. Sci. 41/42, 103-106 (1989).

35. R. B. Doak and D. B. Nguyen, Phys. Rev. B40, 1495-1499 (1989).

36. J. E. Demuth, U. K. Koehler, R. J. Hamers and P. Kaplan, Phys. Rev. Lett. 62, 641-644 (1989).

37. A. Shibata, Y. Kimura and K. Takayanagi, Surf. Sci. Lett. 273, L430-434 (1992).

38. R. Hull, A. E. White, K. T. Short and J. M. Bonar, J. Appl. Phys. 68, 1629 (1990).

39. X. W. Lin, J. Desimoni, H. Bernas, Z. Liliental-Weber and J. Washburn, Mat. Res. Soc. Symp. Proc. 320, 97 (1994).

40. R. C. Dorward and J. S. Kirkaldy, Trans. Met. Soc. AIME, 242, 2055 (1968).

\section{DISCLAIMER}

This report was prepared as an account of work sponsored by an agency of the United States Government. Neither the United States Government nor any agency thereof, nor any of their employees, makes any warranty, express or implied, or assumes any legal liability or responsibility for the accuracy, completeness, or usefulness of any information, apparatus, product, or process disclosed, or represents that its use would not infringe privately owned rights. Reference herein to any specific commercial product, process, or service by trade name, trademark, manufacturer, or otherwise does not necessarily constitute or imply its endorsement, recommendation, or favoring by the United States Government or any agency thereof. The views and opinions of authors expressed herein do not necessarily state or reflect those of the United States Government or any agency thereof. 


\section{Figure Captions}

Figure 1. [110] cross-section TEM image showing subsurface cavity layers formed by implanting $1 \times 10^{17} \mathrm{He} / \mathrm{cm}^{2}$ at $30 \mathrm{keV}$ and annealing a) $1 / 2 \mathrm{hr}$. at $700^{\circ} \mathrm{C}$ and b) $1 \mathrm{hr}$. at $900^{\circ} \mathrm{C}$. a) was imaged at $-1200 \mathrm{~nm}$ defocus and b) at $-600 \mathrm{~nm}$. The elongated cavity indicated with an arrow in b) may have been formed by coalescence.

Figure 2. [110] cross-section TEM image of cavities in Si formed by implanting a) $1 \times 10^{16}$ $\mathrm{He} / \mathrm{cm}^{2}$ and b) $2 \times 10^{16} \mathrm{He} / \mathrm{cm}^{2}$, both at $30 \mathrm{keV}$, and annealing $1 / 2 \mathrm{hr}$. at $700^{\circ} \mathrm{C}$. a) was imaged at $-1200 \mathrm{~nm}$ defocus and b) at $-600 \mathrm{~nm}$.

Figure 3. Monte Carlo simulation of He depth distribution for $2 \times 10^{16} \mathrm{He} / \mathrm{cm}^{2}$ implanted at 30 $\mathrm{keV}$, obtained using TRIM 90 and scaled in depth to $\mathrm{R}_{\mathrm{p}}=300 \mathrm{~nm}$. The dashed lines indicate the threshold concentration, 1.6 at.\% He, inferred from the $65 \mathrm{~nm}$ cavitylayer thickness seen with TEM.

Figure 4. Size Distribution of cavities obtained for $1 \times 10^{17} \mathrm{He} / \mathrm{cm}^{2}$ implanted at $30 \mathrm{keV}$ and annealed $10 \mathrm{hr}$. at $800^{\circ} \mathrm{C}$.

Figure 5. [110] cross-section TEM image of cavities produced by implanting $2 \times 10^{16} \mathrm{He} / \mathrm{cm}^{2}$ at $130 \mathrm{keV}$ and annealing $1 / 2 \mathrm{hr}$. at $700^{\circ} \mathrm{C}$, followed by 5 minutes at $1180^{\circ} \mathrm{C}$ in $\mathrm{H}_{2}$, and growing $1.5 \mu \mathrm{m}$ of epitaxial $\mathrm{Si}$ by CVD at $1120^{\circ} \mathrm{C}$. (TEM image by T. J. Headley).

Figure 6. Electron diffraction pattern taken from a plan-view specimen of (001) Si implanted with $1 \times 10^{17} \mathrm{Cu} / \mathrm{cm}^{2}$ at $150 \mathrm{keV}$ after annealing $6 \mathrm{hr}$. at $600^{\circ} \mathrm{C}$. The bright rings (marked) are those of $\mathrm{Si}$; the others fit $\eta-\mathrm{Cu}_{3} \mathrm{Si}$, as shown in Table II.

Figure 7. Depth-integrated amount of $\mathrm{Cu}$ observed trapped at cavity layer after annealing for the indicated times at $873 \mathrm{~K}\left(600^{\circ} \mathrm{C}\right)$. The cavities were initially formed by ion implanting $1 \times 10^{17} \mathrm{He} / \mathrm{cm}^{2}$ at $30 \mathrm{keV}$ and annealing $1 / 2 \mathrm{hr}$. at $700^{\circ} \mathrm{C}$; the $\mathrm{Cu}$ was gettered from $\eta-\mathrm{Cu}_{3} \mathrm{Si}$ on the other side of the $250 \mu \mathrm{m}$-thick wafer.

Figure 8. High-resolution (lattice) image of a cavity in $\mathrm{Si}$ formed by implanting $\mathrm{He}$ and annealing $1 \mathrm{hr}$. at $900^{\circ} \mathrm{C}$, and then implanting $\mathrm{Cu}$ on the other side of the wafer and annealing $26 \mathrm{hr}$. at $600^{\circ} \mathrm{C}$ to saturate the cavities with trapped $\mathrm{Cu}$. Prominent facets are indicated.

Figure 9. Depth profiles of trapped $\mathrm{Cu}$ obtained with $\mathrm{RBS}$ for cavity layers formed with four implantation (all $30 \mathrm{kev}$ ) and anneal treatments: $1 \times 10^{17} \mathrm{He} / \mathrm{cm}^{2}, 1 / 2 \mathrm{hr}$. at $700^{\circ} \mathrm{C}$; $1 \times 10^{17} \mathrm{He} / \mathrm{cm}^{2}, 1 \mathrm{hr}$. at $900^{\circ} \mathrm{C} ; 2 \times 10^{16} \mathrm{He} / \mathrm{cm}^{2}, 1 / 2 \mathrm{hr}$. at $700^{\circ} \mathrm{C}$; and $1 \times 10^{16} \mathrm{He} / \mathrm{cm}^{2}$, $1 / 2 \mathrm{hr}$ at $700^{\circ} \mathrm{C}$.

Figure 10. Depth-integrated amount of Au observed trapped at cavity layer after annealing for the indicated times at $1073 \mathrm{~K}\left(800^{\circ} \mathrm{C}\right)$ and $1123 \mathrm{~K}\left(850^{\circ} \mathrm{C}\right)$. The cavities were 
formed by ion implanting $1 \times 10^{17} \mathrm{He} / \mathrm{cm}^{2}$ at $150 \mathrm{keV}$ on the opposite side of the 250 $\mu \mathrm{m}$-thick wafer from the implanted Au. The solid lines show the initial buildup of trapped solute expected using accepted solubility and diffusivity values in our model.

Figure 11. a) Bright-field TEM image of $\mathrm{NiSi}_{2}$ particle in a layer on (001) Si implanted with $1 \times 10^{17} \mathrm{Ni} / \mathrm{cm}^{2}$ at $150 \mathrm{keV}$ and annealed 64 hours at $700^{\circ} \mathrm{C}$, b) [112], c) [111] and d) [110] convergent beam microdiffraction patterns from the particle obtained after tilting through the correct angles for these zones of a fcc lattice.

Figure 12. Depth profiles obtained with SIMS for $\mathrm{Fe}$ and $\mathrm{Co}$ in a cavity layer after gettering from their silicides on the opposite side of the wafer after $2 \mathrm{hr}$. at $1273 \mathrm{~K}\left(1000^{\circ} \mathrm{C}\right)$ and $2 \mathrm{hr}$. at $1173 \mathrm{~K}\left(900^{\circ} \mathrm{C}\right)$, respectively. The TRIM profile for the $1 \times 10^{17} \mathrm{He} / \mathrm{cm}^{2}$ implant at $150 \mathrm{keV}$ is also shown.

Figure 13. Predicted reduction in $\mathrm{Cu}$ solution concentration attained by introducing cavities into a $1 \mathrm{~mm}$-thick $\mathrm{Si}$ wafer and gettering at $600^{\circ} \mathrm{C}$. The solid solubility of $\mathrm{Cu}$ at this temperature is also indicated.

Figure 14. Depth profile obtained with SIMS of O gettered to cavity layer formed by implanting $5 \times 10^{16} \mathrm{He} / \mathrm{cm}^{2}$ at $130 \mathrm{keV}$ into $\mathrm{CZ} \mathrm{Si}$ and annealing $1 / 2 \mathrm{hr}$. at $700^{\circ} \mathrm{C}$ followed by 1 hr. at $1000^{\circ} \mathrm{C}$, both in dry $\mathrm{O}_{2}$. 
Table I. Summary of Cavity Microstructures and Surface Trapping Sites

\begin{tabular}{|c|c|c|}
\hline Fluence: & $2 \times 10^{16} \mathrm{He} / \mathrm{cm}^{2}$ & $1 \times 10^{17} \mathrm{He} / \mathrm{cm}^{2}$ \\
\hline eal: & hr. $700^{\circ} \mathrm{C}$ & $0^{\circ} \mathrm{C} \quad 1 / 2 \mathrm{hr} .800^{\circ} \mathrm{C} \quad 8 \mathrm{hr} .800^{\circ} \mathrm{C} 1 \mathrm{hr} .900^{\circ} \mathrm{C} \quad 1 / 2 \mathrm{hr} .1000^{\circ} \mathrm{C}$ \\
\hline
\end{tabular}

$\begin{array}{lllllll}\text { Avg. Diameter (nm) } & 10.3 & 8.5 & 13.3 & 16 & 20 & 28\end{array}$

${ }^{a}$ Areal Density

of Cavities $\left(\mathrm{cm}^{-2}\right)$

$$
2.6 \times 10^{11} \quad 2.9 \times 10^{12}
$$

$6 \times 10^{11}$

$3.1 \times 10^{11}$

${ }^{\text {a }}$ Cavity Volume per

Wafer Area $\left(\mathrm{nm}^{3} / \mathrm{nm}^{2}\right)$

2.3

12.4

16

15

${ }^{\text {a }}$ Cavity Area to

Wafer Area Ratio

0.9

4.5

${ }^{\mathrm{b}}$ Calculated Trap Sites

per Wafer Area $\left(\mathrm{cm}^{-2}\right)$

$0.6 \times 10^{15}$

$4.7 \times 10^{15}$

$3.2 \times 10^{15}$

$2.6 \times 10^{15}$

${ }^{\mathrm{c}}$ Trapped Solute per

Wafer Area (at. $/ \mathrm{cm}^{2}$ ) $\quad 0.8 \times 10^{15} \mathrm{Cu}$

$4.8 \times 10^{15} \mathrm{Cu}$

${ }^{\mathrm{d}} 3.2 \times 10^{15} \mathrm{Au} \quad 2.3 \times 10^{15} \mathrm{Cu}$

${ }^{a}$ Measured with TEM and normalized to the wafer front surface area.

Uncertainties in area normalized measurements: $\pm 25 \%$ for $2 \times 10^{16} \mathrm{He} / \mathrm{cm}^{2}, \pm 15 \%$ for $1 \times 10^{17} \mathrm{He} / \mathrm{cm}^{2}$.

${ }^{\mathrm{b}}$ Cavity/Wafer Area Ratio multiplied by an assumed areal density of 7 sites $/ \mathrm{nm}^{2}$.

${ }^{c}$ Saturated trapped amount of $\mathrm{Cu}$ or $\mathrm{Au}$ as measured with RBS.

${ }^{\mathrm{d}}$ Au trapping was measured at a slightly higher temperature of $850^{\circ} \mathrm{C}$. 
Table II. Copper Silicide Diffraction

Observed in Cu-Implanted Si

d (A) Intensity/Completeness

3.50 very weak, partial ring

3.24 very weak, partial ring

2.54

2.45 weak, full ring

2.31 weak, partial ring

2.12 medium, partial ring

2.02 strong, full ring

- overlaps Si (1.920) -

1.83 weak, partial ring

1.79 weak, partial ring - overlaps Si (1.566) -

1.43 medium, partial ring

1.22 weak, partial ring

1.17 medium, full ring
$\frac{\mathrm{Hex} . \mathrm{Cu}_{3}}{\text { Si } \frac{\mathrm{Si}(\AA)}{\text { Calculated / Observed [22] }}}$

$3.50(10 \overline{1} 0)$

$2.44(0001)$

$2.02(11 \overline{2} 0) / 2.03$ strong

$2.00(10 \overline{1} 1) / 2.01$ strong

$1.75(20 \overline{2} 0)$

$1.56(11 \overline{2} 1)$

$1.42(20 \overline{2}$ l) / 1.43 strong

$1.22(0002)$

$1.17(30 \overline{3} 0) / 1.17$ strong
$\underline{\eta}-\mathrm{Cu}_{3} \underline{\mathrm{Si}}$

Ref. [23]

2.575 strong

2.226 strong

2.057 very strong

2.022 strong

1.993 strong

1.893 very strong

1.567 strong

1.423 weak

1.318 weak

1.230 strong

$1.172,1.165$ weak;

1.158 strong 
Table III. Summary of Solute Trapping Observations

\begin{tabular}{|c|c|c|c|c|c|}
\hline \multirow[t]{2}{*}{ Meta } & \multicolumn{2}{|c|}{ Amount Trapped Solute } & $\{111\}$ Ordere & Silicide & ${ }^{*}$ Chemisorbed \\
\hline & $\left(10^{12} \mathrm{~cm}^{-2}\right)$ & (ML) & Phase (ML) & $\overline{\text { Energy }}(\mathrm{eV})$ [3] & Energy $(\mathrm{eV})$ \\
\hline $\mathrm{Cu}$ & 4800 & 1.0 & $\sim 1$ & $1.5-1.7$ & $2.2 \pm 0.2$ \\
\hline $\mathrm{Au}$ & 3200 & 1.0 & $\sim 1$ & $\sim 2.5^{\dagger}$ & $\geq 2.0$ \\
\hline $\mathrm{Ni}$ & 150 & 0.057 & $1 / 19$ & 1.7 & $\geq 1.5$ \\
\hline Co & 7 & 0.0026 & $1 / 7$ & 2.8 & $\sim 1.7$ \\
\hline & 12 & 0.0062 & $\sim 1 / 2$ & $\sim 2.9$ & $\sim 1.6$ \\
\hline
\end{tabular}

* Cavity binding, expressed relative to solution in the Si lattice

${ }^{\dagger}$ Molten Si-Au alloy at the measurement temperatures. 
(1)

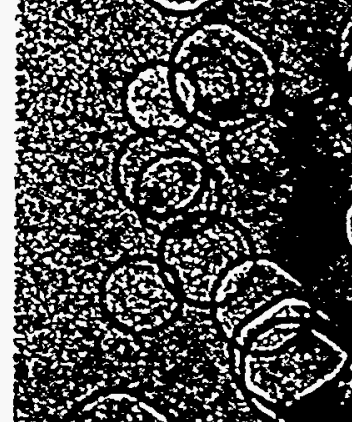

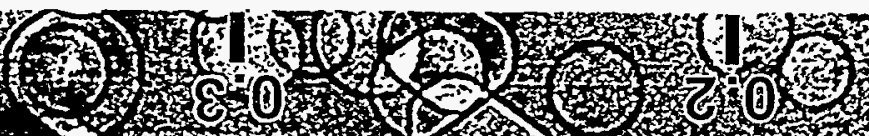
(9)
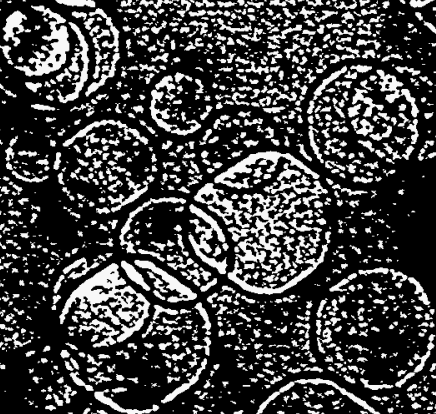

(2).

i.
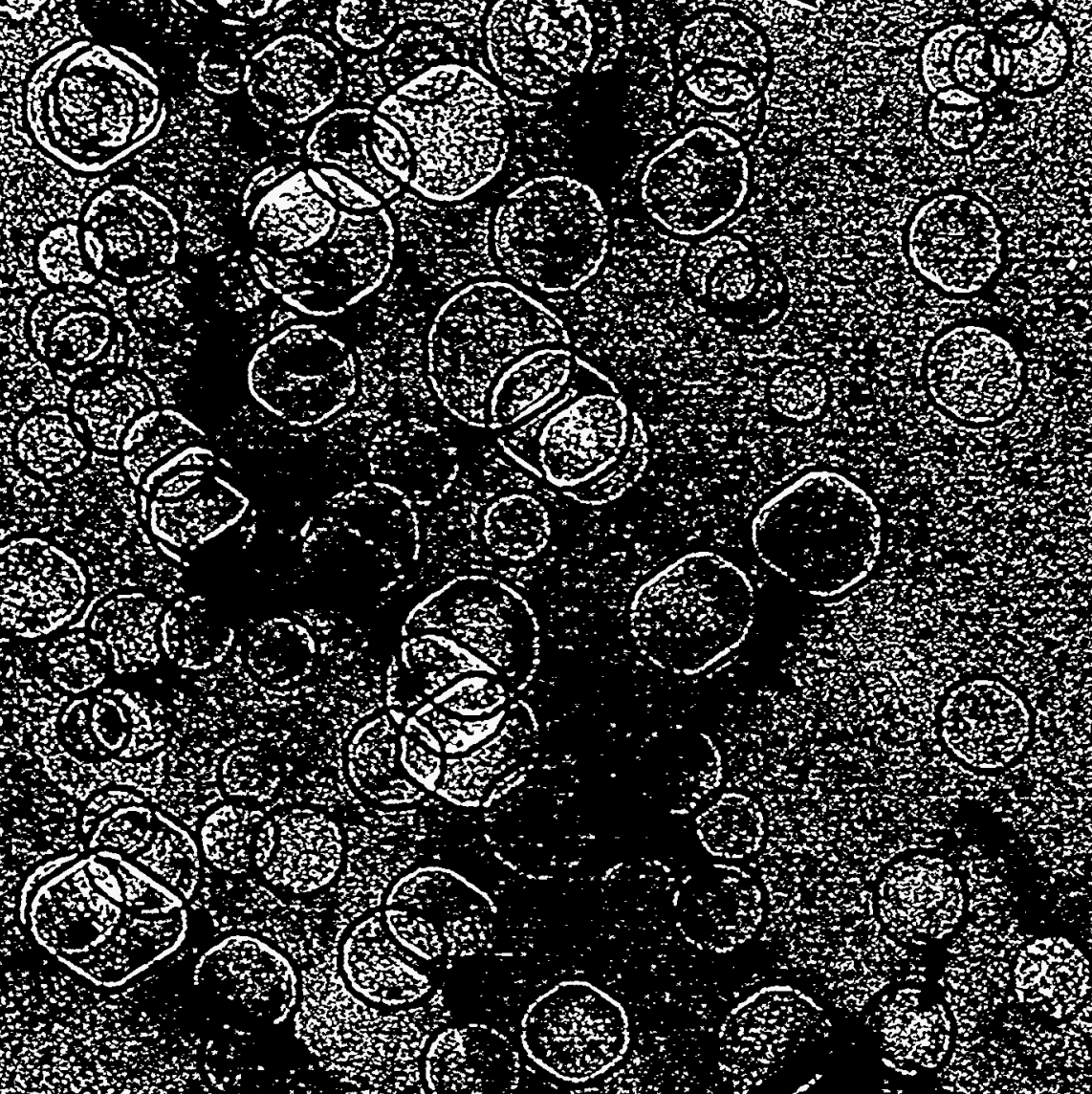

01
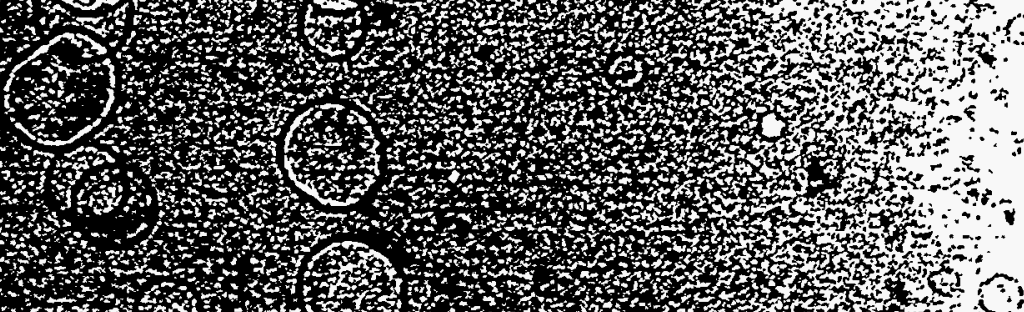

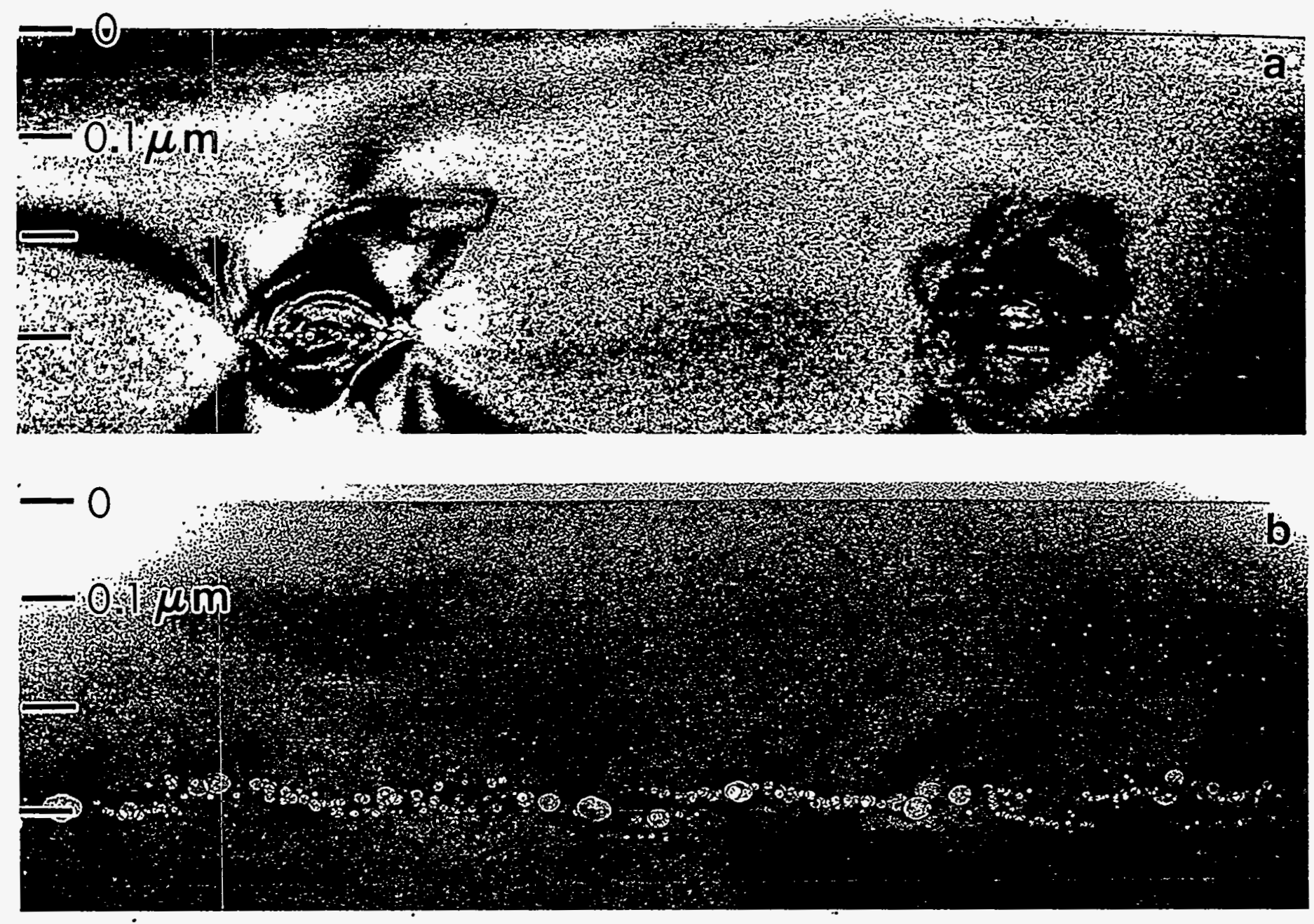


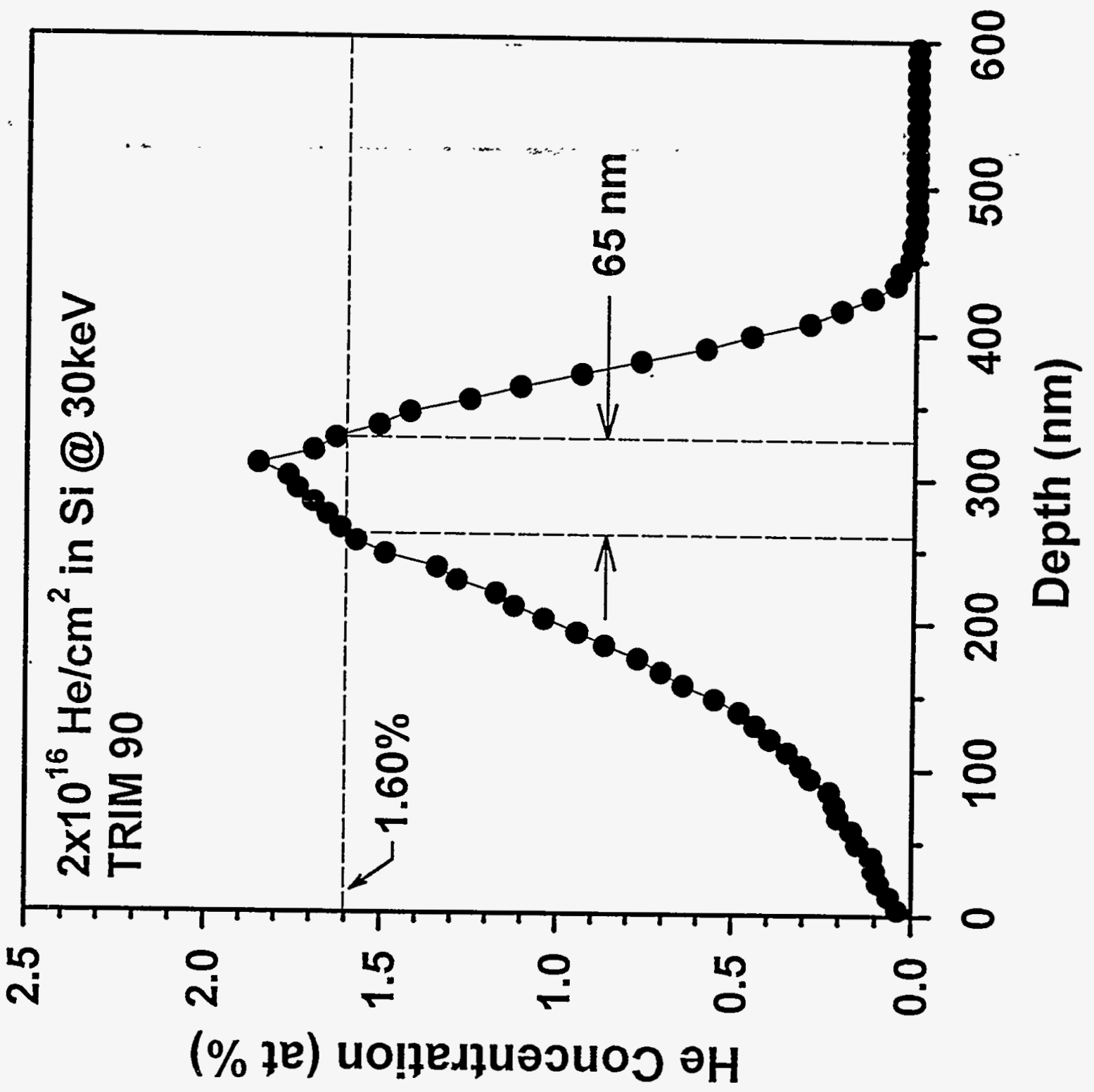


Origied

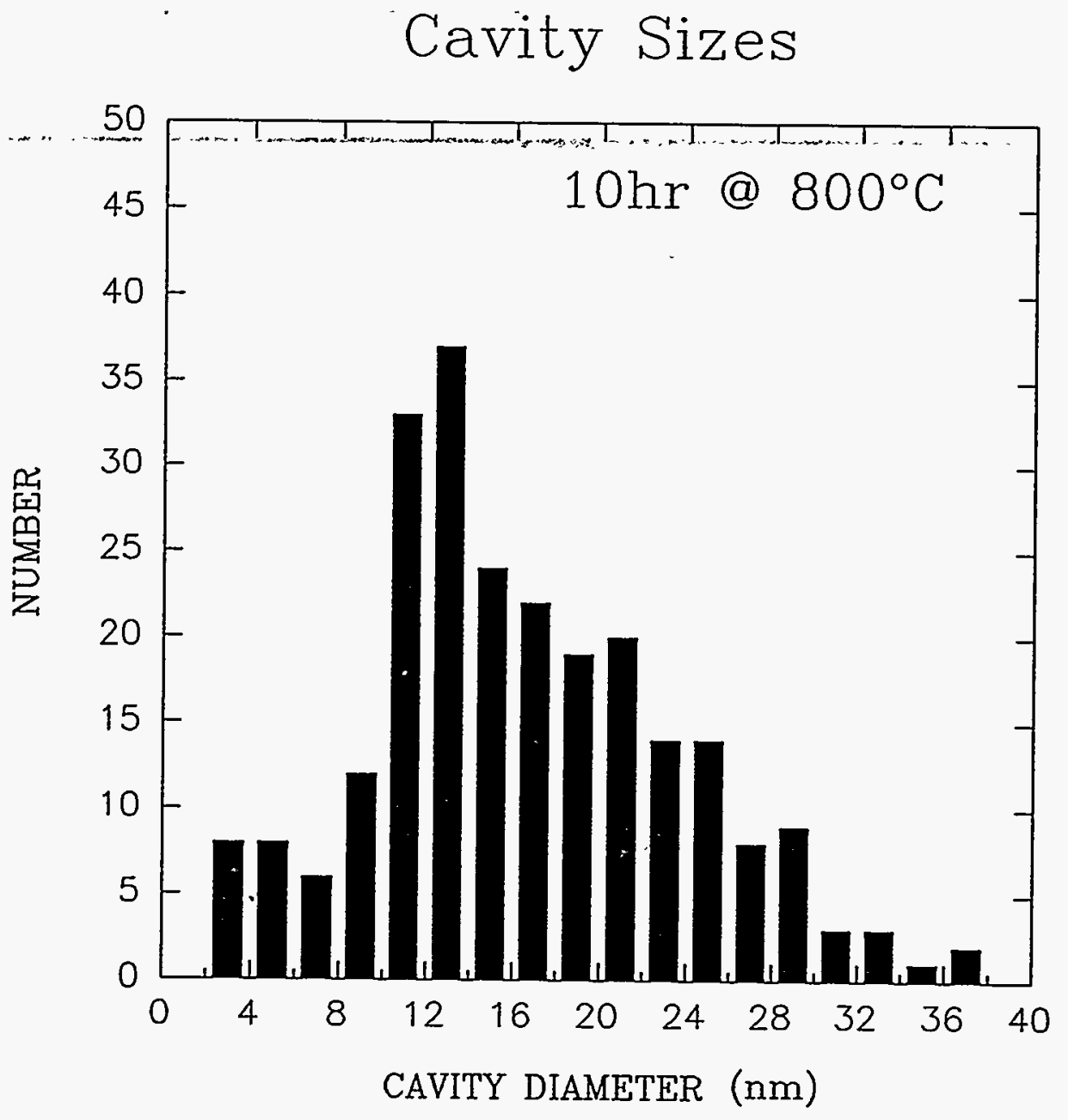




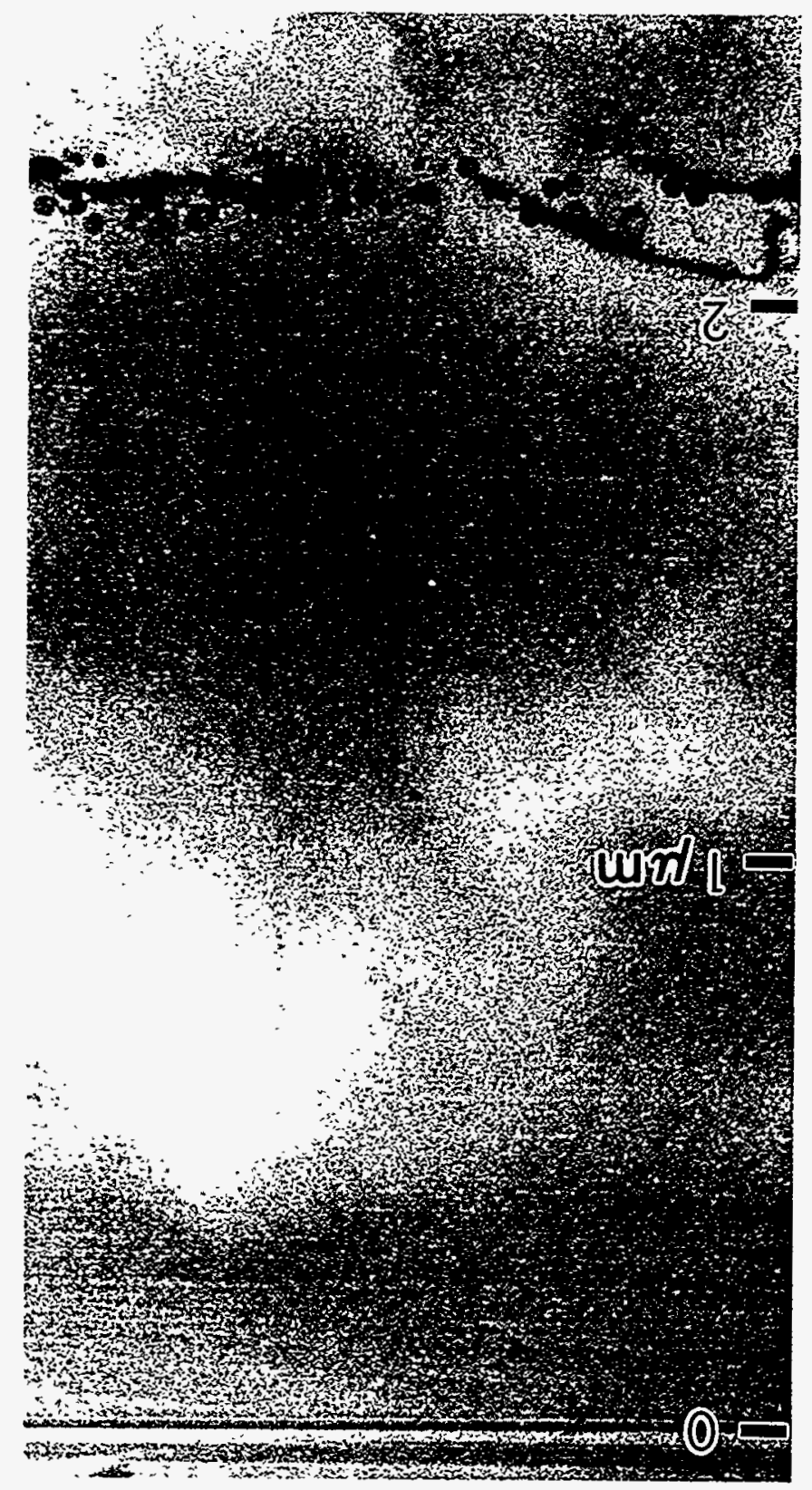




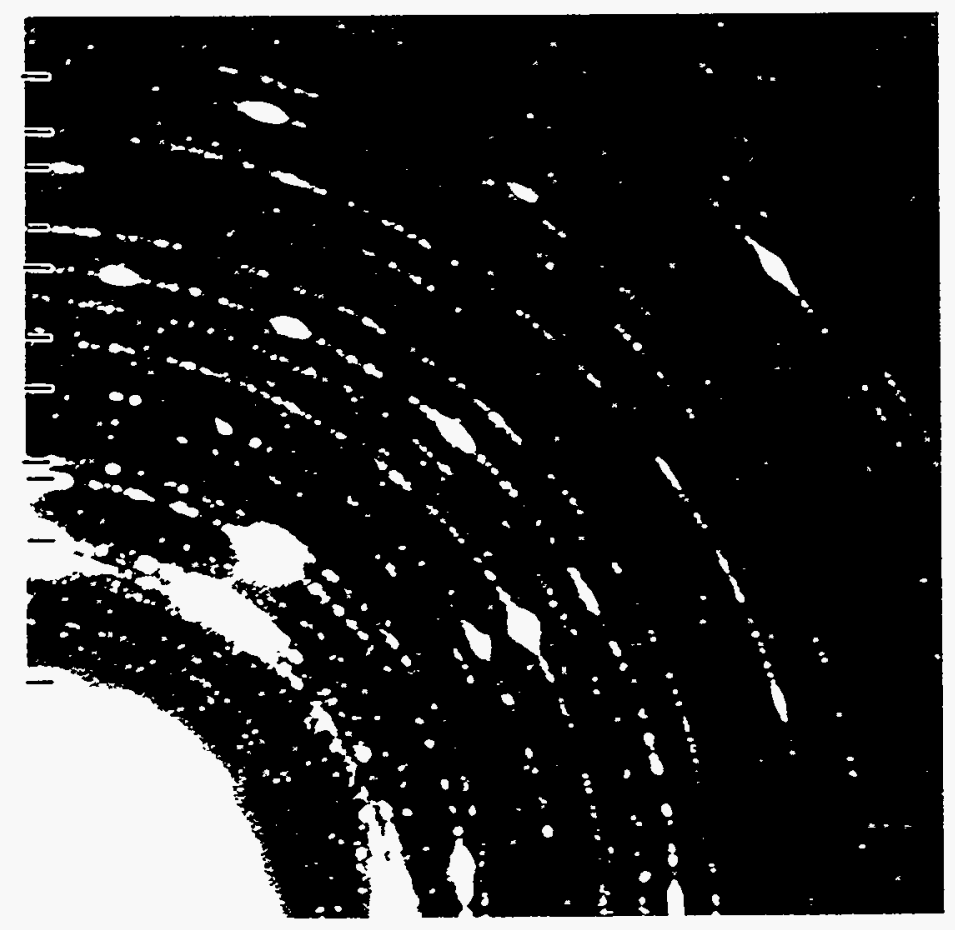




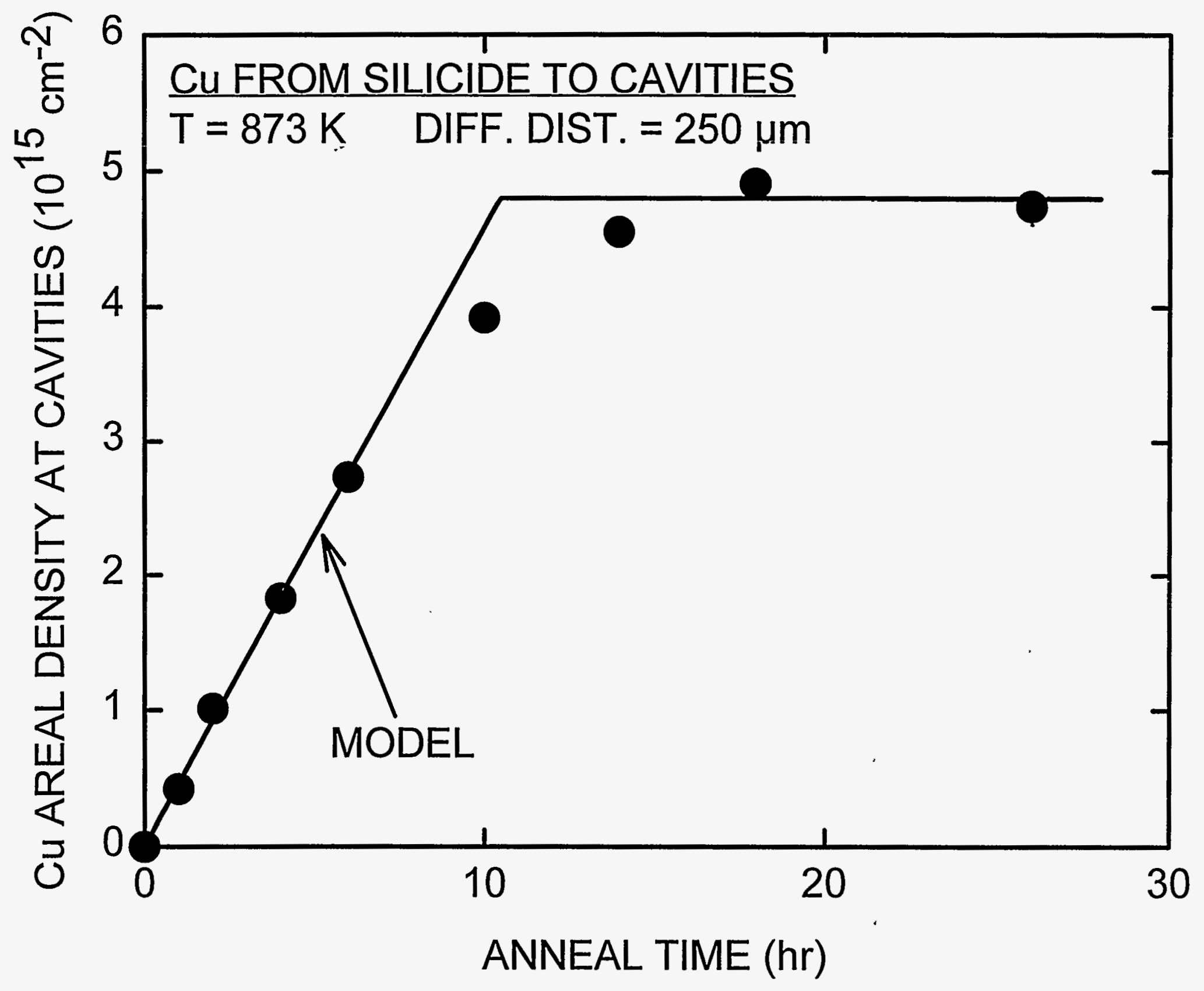




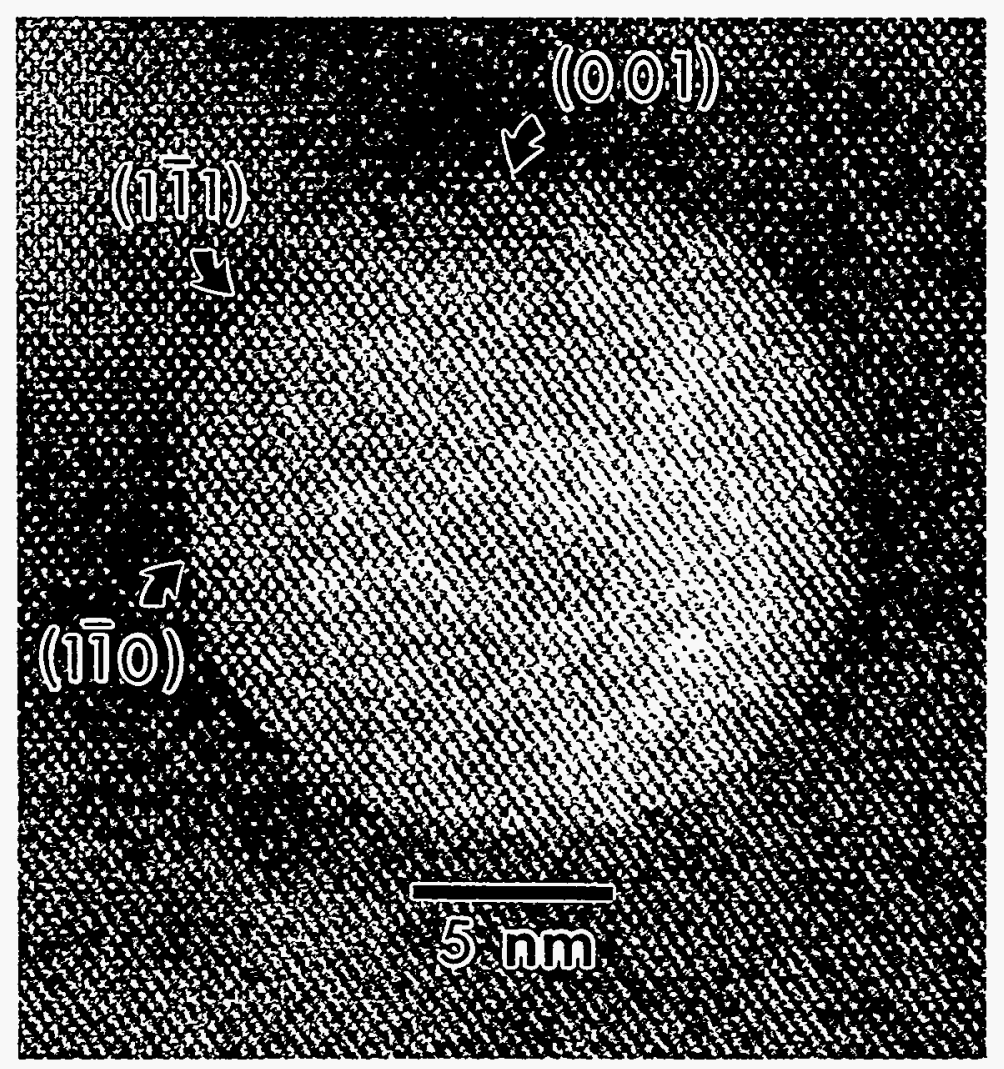




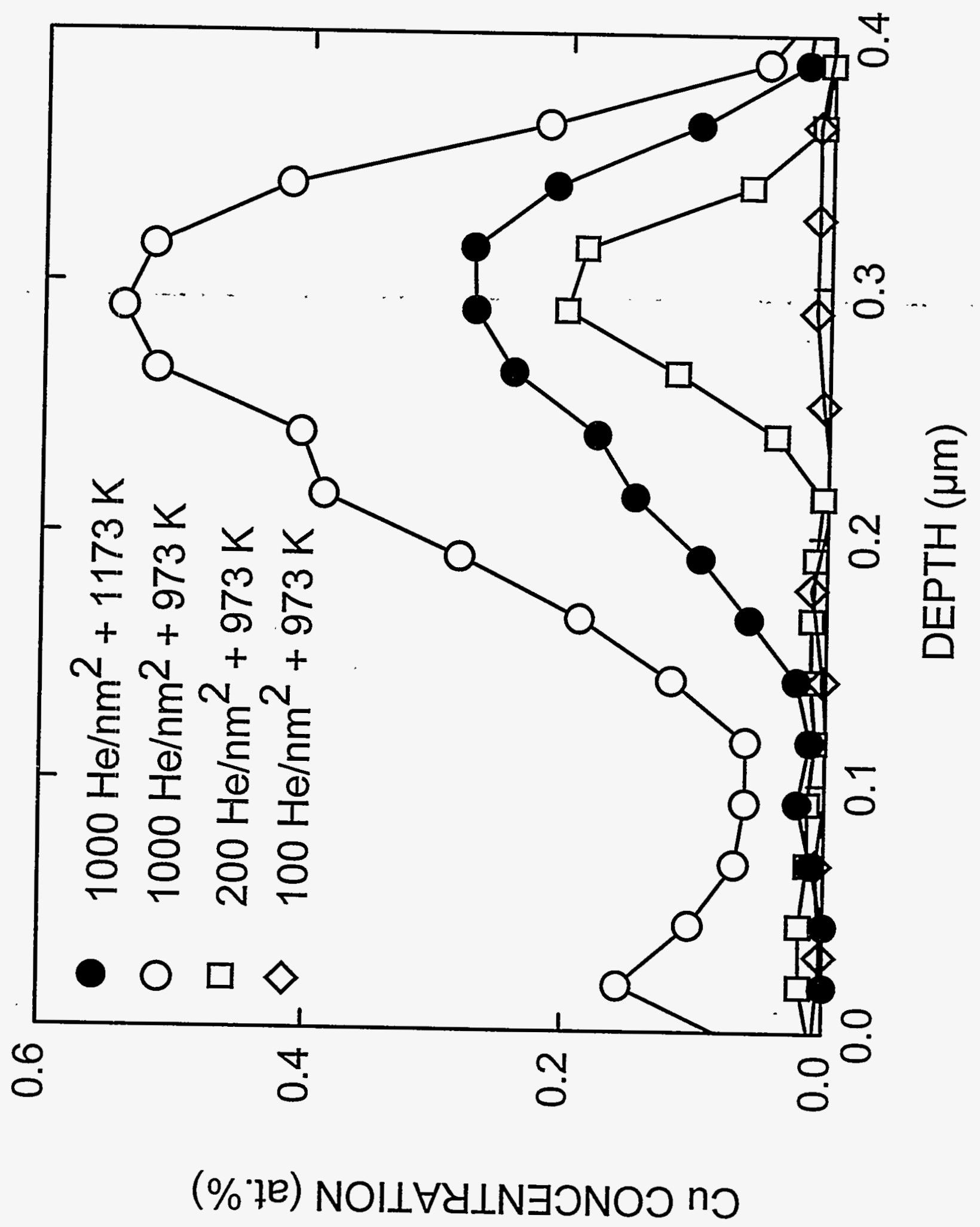




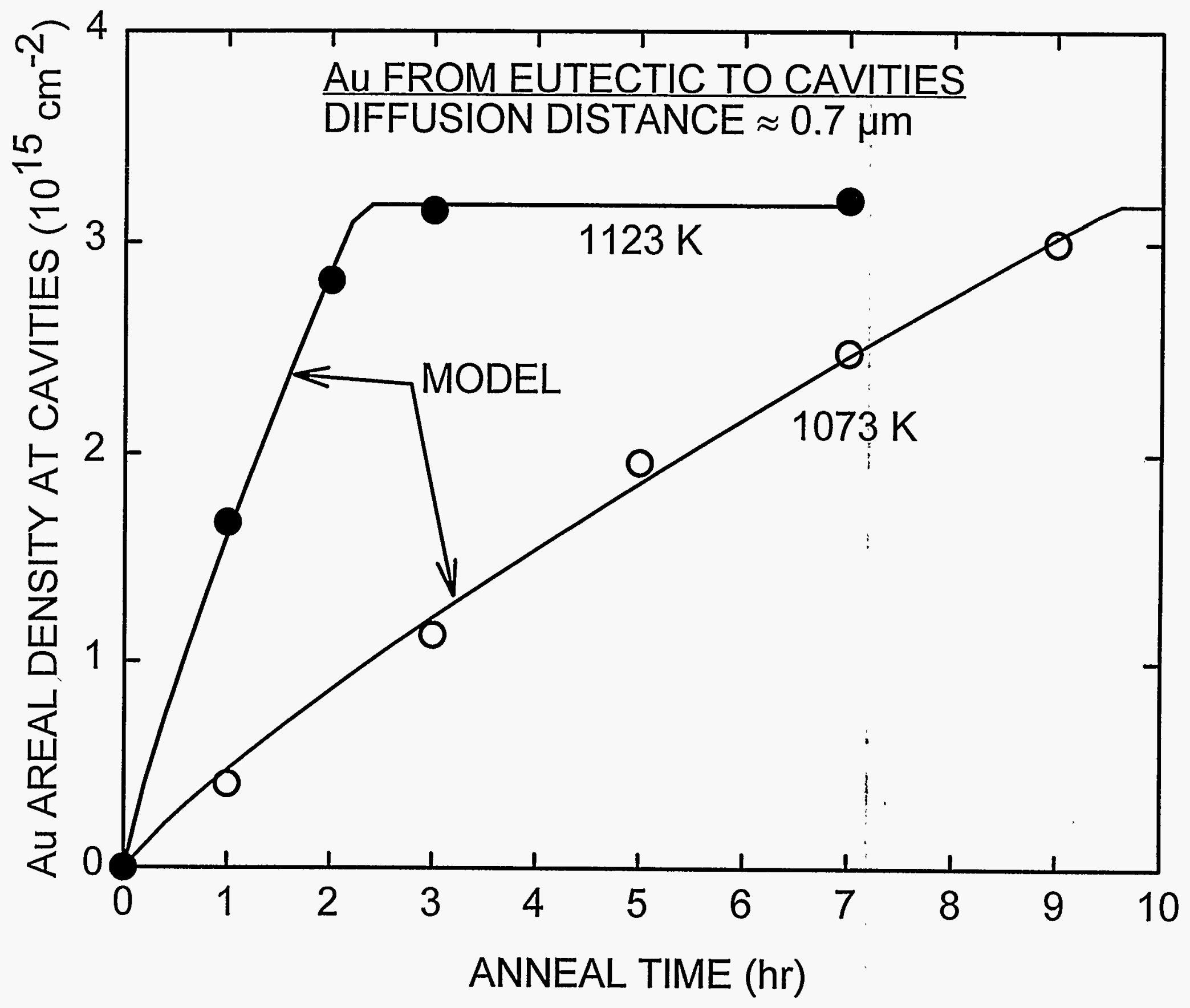



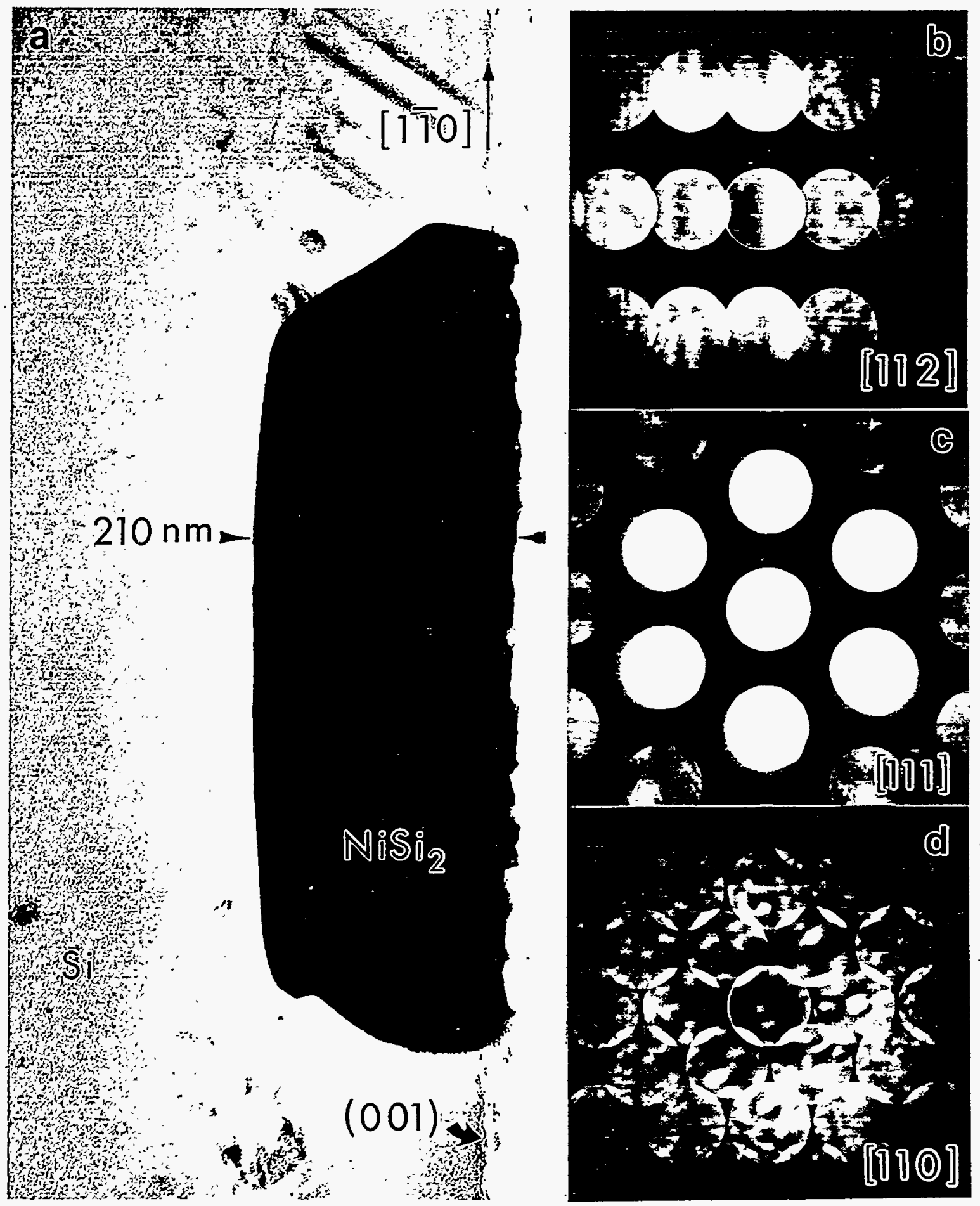


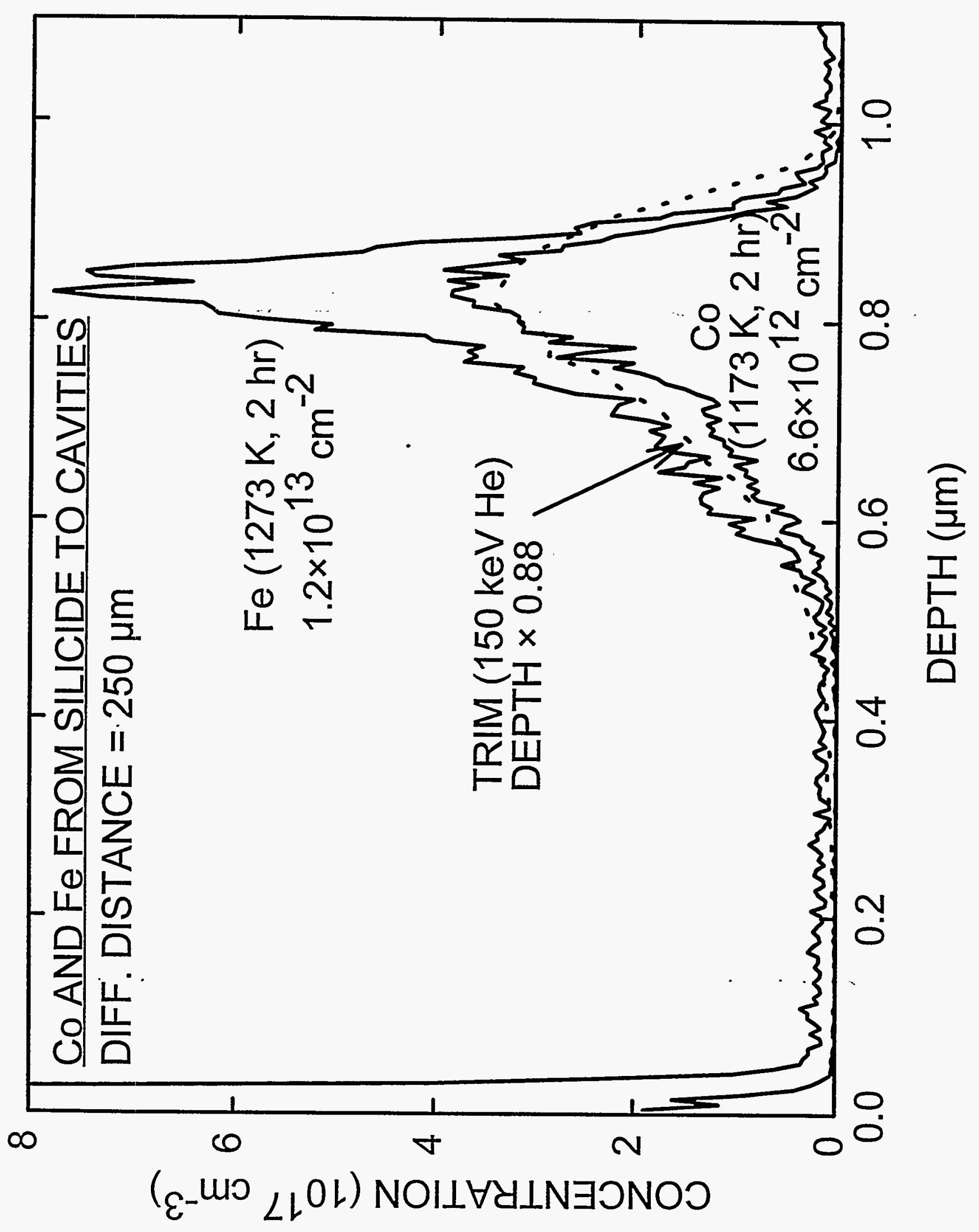


LOG CONC. AFTER GETTERING $\left(\mathrm{cm}^{-3}\right)$

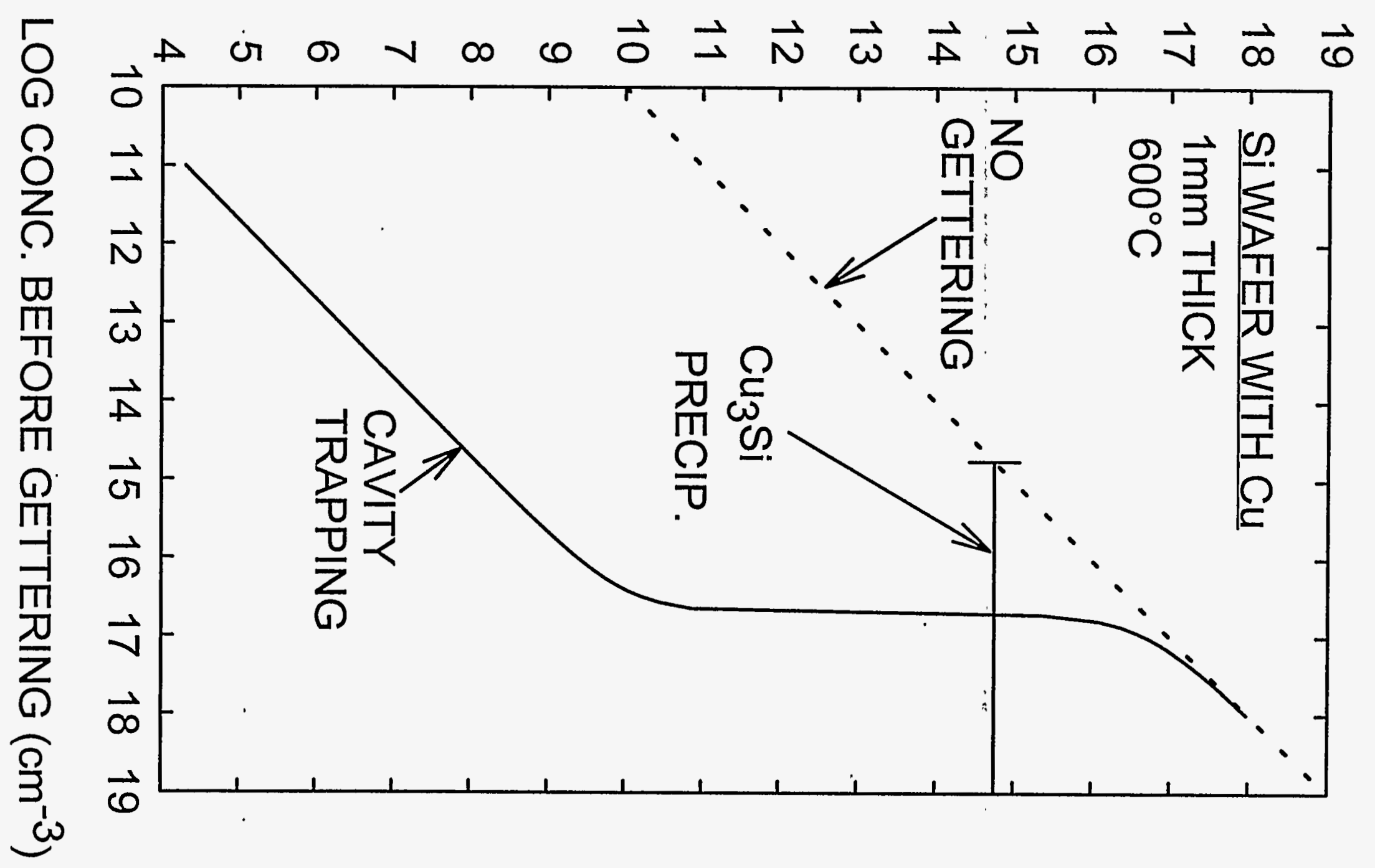




\section{OXYGEN CONCENTRATION $\left(\mathrm{cm}^{-3}\right)$}

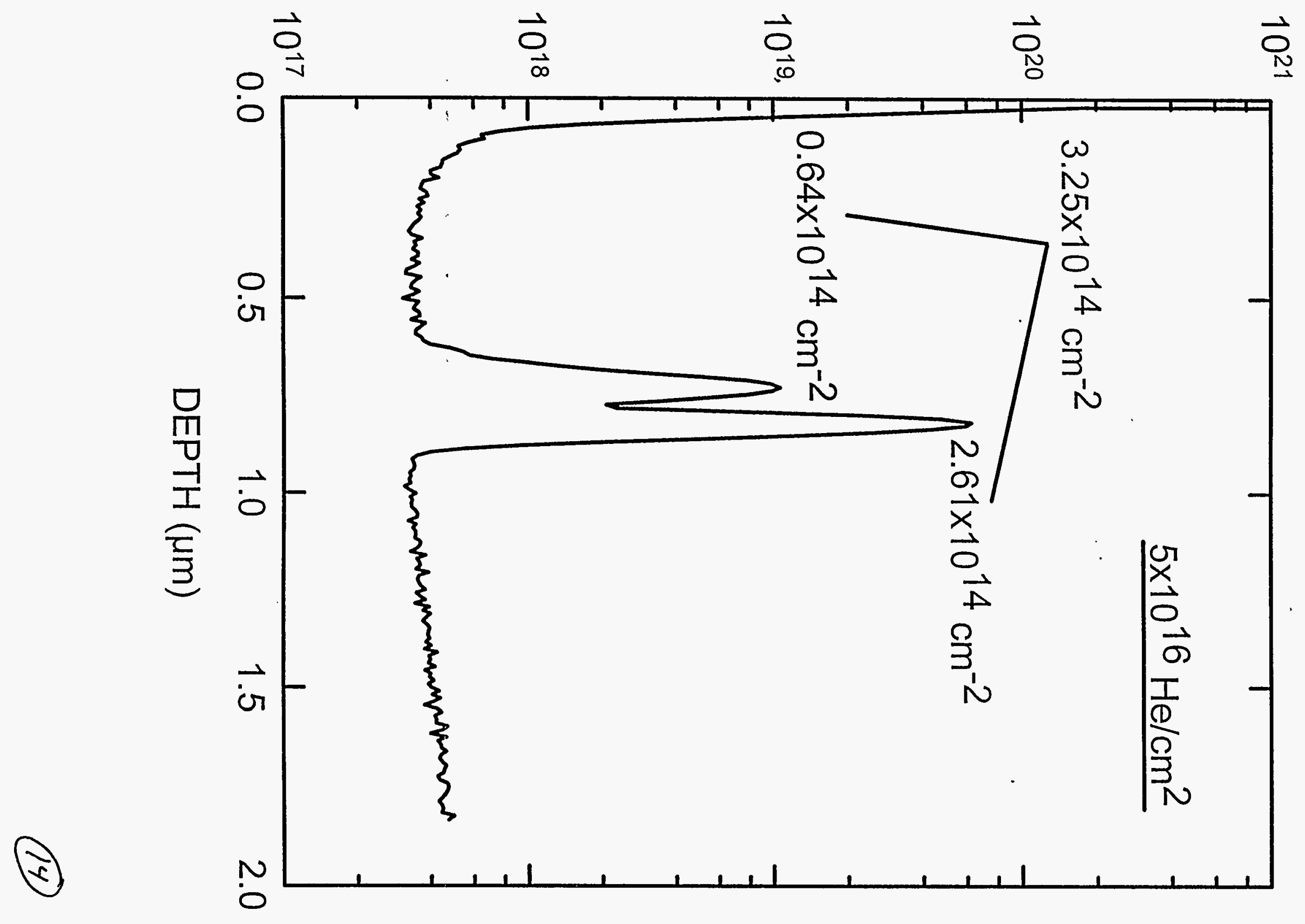

